\title{
Temporal Trends and Spatial Patterns of Temperature and Its Extremes over the Beijing-Tianjin Sand Source Region (1960-2014), China
}

\author{
Wei Wei $\mathbb{D},{ }^{1}$ Baitian Wang $\mathbb{D},{ }^{1}$ Kebin Zhang $\mathbb{D},{ }^{1}$ Zhongjie Shi $\mathbb{D},{ }^{2}$ \\ Genbatu Ge, ${ }^{2}$ and Xiaohui Yang ${ }^{2}$ \\ ${ }^{1}$ College of Water and Soil Conservation, Beijing Forestry University, Beijing 100083, China \\ ${ }^{2}$ Institute of Desertification Studies, Chinese Academy of Forestry, Beijing 100091, China \\ Correspondence should be addressed to Baitian Wang; wbaitian@bjfu.edu.cn and Kebin Zhang; ctccd@126.com
}

Received 9 December 2017; Accepted 24 January 2018; Published 10 July 2018

Academic Editor: Harry D. Kambezidis

Copyright (c) 2018 Wei Wei et al. This is an open access article distributed under the Creative Commons Attribution License, which permits unrestricted use, distribution, and reproduction in any medium, provided the original work is properly cited.

In order to examine temperature changes and extremes in the Beijing-Tianjin Sand Source Region (BTSSR), ten extreme temperature indices were selected, categorized, and calculated spanning the period 1960-2014, and the spatiotemporal variability and trends of temperature and extremes on multitimescales in the BTSSR were investigated using the Mann-Kendall (M-K) test, Sen's slope estimator, and linear regression. Results show that mean temperatures have increased and extreme temperature events have become more frequent. Annual temperature has recorded a significant increasing trend over the BTSSR, in which 51 stations exhibited significant increasing trends $(p<0.05)$; winter temperature recorded the most significant increasing trend in the northwest subregion. All extreme temperature indices showed warming trends at most stations; a higher warming slope in extreme temperature mainly occurred along the northeast border and northwest border and in the central-southern mountain area. As extreme low temperature events decrease, vegetation damage due to freezing temperatures will reduce and low cold-tolerant plants may expand their distribution range northward to revegetate barren areas in the BTSSR. However, in water-limited areas of the BTSSR, increasing temperatures in the growing season may exacerbate stress associated with plants relying on precipitation due to higher temperatures combining with decreasing precipitation.

\section{Introduction}

As highlighted by the IPCC, climate change is the most important environmental problem and the greatest challenge facing mankind [1]. From 1951 to 2012, global average surface temperatures are reported to have risen by 0.72 degrees [1]; as temperatures have increased, extreme climatic events, which can be sudden and destructive, have also increased in frequently, and their occurrence directly or indirectly has resulted in prominent social problems and natural disasters [2], especially in ecologically fragile areas. Recent global temperature extremes [3] indicate that the number of cold days, cold nights, and frost days has decreased while the number of warm days and warm nights has increased [3], these changes having obvious regional characteristics [47].
Global regional-scale temperature changes are currently well documented. For example, Rehman and Al-Hadhrami [8] showed that the annual average maximum temperature on the west coast of Saudi Arabia has increased more than the average minimum temperature, while Khomsi et al. [9] recorded that hot and very hot events during the summer in Morocco (Safi and Marrakech) showed statistically significant decreasing trends. The number of very cold nights recorded annually and during the winter has significantly decreased across the Basilicata region (southern Italy) over the period 1951-2010, while the frequency of cold days has shown a weak increase [10]. Extreme temperature indices have indicated steady warming trends for arid and semiarid areas of southeastern Kenya [11], while days with 1-day extreme minimum or maximum apparent temperature have exhibited an increasing trend across many 
stations in the United States [12]. Temporal and spatial distribution of extreme temperatures across China shows that hot extremes indicate an upward trend, while cold extremes show downward trends; between 1961 and 2011, more frequent extreme temperature events were recorded in the southern area of the major grain producing region in China [13] and some trends of extreme temperature indices in the Songhua River Basin were stronger than those recorded in the Yangtze River Basin, southwestern China, and the Tibetan Plateau. Zhong et al. [14] also found the number of warm nights, warm days, and summer days would be more significant at higher latitudes. Sun et al. [15], investigating extreme temperature events in the Loess Plateau, found that the trend magnitudes of cold extremes were greater than those of warm extremes and that the growing season increased and diurnal temperature ranges declined in the region.

Surface temperature changes have been mainly considered to be due to anthropogenic activities, especially due to changes in concentrations of greenhouse gases (GHG) [16, 17]. In areas surrounding Beijing and Tianjin, a large amount of land was reclaimed in the 1960s which destroyed the surface vegetation and caused mobile and semimobile sand dunes to expand [18]. Since the implementation of the reform and development policy (1979), environmental degradation has continued to intensify in these areas due to over grazing and excessive reclamation of grasslands [19, 20]; as a result, the Beijing, Tianjin, and Hebei areas experienced huge dust storms during March to April in the year 2000. To improve the environment of these areas, the Chinese government established the sand source control project (phase $I$ ) in the Beijing-Tianjin Sand Source Region (BTSSR) in the year $2000[21,22]$. Following the implementation of this project, more than half of the land in this region has experienced an increase in vegetation productivity during 2000-2010 [23]. Studies on the characteristics of climate change and the response of vegetation cover to weather changes in this region have found that NDVI has recorded a slight increasing trend in the growing season [24, 25]. In order to consolidate the results of phase $I$ of the Blown-Sand Control Project, and to further reduce sandstorm hazards and construct the northern ecological barrier, phase II has been implemented, spanning the period 2013-2022. However, with continued increasing temperatures, decreasing precipitation, and enlarging of the drought area, it is very difficult to consolidate the achievements of phase $I$ and to implement and improve the construction of phase $I I$ at the same time $[23,26]$. Evaluation of extreme climate changes in the BTSSR can identify factors causing regional environmental and social problems and provide reference for the construction of phase II to cope with extreme climatic events and to improve disaster prevention and mitigation work in this area.

The objectives of this study, therefore, are (1) to undertake trend analysis of temperature and extremes in the BTSSR; (2) to investigate the spatial patterns of trends of temperature and extremes; (3) and to discuss the possible impact temperature and extremes have on vegetation.

\section{Study Area}

The study area, located at the scope of the phase II project in the BTSSR, includes six provinces with 138 counties. This area includes the Mu Us Sandland, situated between Yulin city (Shaanxi province) and Erdos city (Inner Mongolia), and the Kubuqi Desert, situated in the northern Ordos Plateau. The region covers an area of $71.05 \times 10^{4} \mathrm{~km}^{2}$ (approximately $36^{\circ} \sim$ $46^{\circ} \mathrm{N}, 107^{\circ} \sim 119^{\circ} \mathrm{E}$; Figure 1). The area of land desertification covers an area of $22.69 \times 10^{4} \mathrm{~km}^{2}$, exceeding one-third of the total area of phase II [22].

The climate in the study region is complex, including temperate semihumid, semiarid, arid, and extremely arid climate types [27]. Annual precipitation across the area varies from 105 to $743 \mathrm{~mm}$, with the majority of precipitation occurring from June to September. Average temperature is $6.2^{\circ} \mathrm{C}$ with significant regional differences, such as a maximum temperature of $12.7^{\circ} \mathrm{C}$ in Beijing and a minimum temperature of $-2.6^{\circ} \mathrm{C}$ in Arxan, Inner Mongolia. The average sunshine duration is $7.9 \mathrm{~h} / \mathrm{d}$, and the regional mean wind speed is $4.5 \mathrm{~m} / \mathrm{s}$. The average growing season length is 206 days. In general, the climate of the BTSSR is dry, windy, and has a low temperature, with climatic characteristics varying significantly across the region.

\section{Data and Methods}

3.1. Data Source, Quality Control, and Homogeneity Test. Daily temperature data from the BTSSR was provided by the China Meteorological Data Network (http://data.cma.cn/). When more than $10 \%$ of daily temperature data was missing, or more than three months contained more than $20 \%$ missing days, annual temperature records were deemed as missing. To ensure data integrity and consistency, meteorological stations lacking more than $75 \%$ of a year's temperature records were omitted; missing days were not superseded by estimated daily temperature values [28, 29]. A total of 53 stations evenly distributed across the BTSSR were selected for this study; data from these stations spanned the period from 1960 to 2014 (Figure 1).

Quality control of the data was undertaken using the RClimDex package developed by Zhang and Yang [30], a control package that has been previously applied to test climate data [31]. The RClimDex package enabled errors in the data to be eliminated, including errors in manual keying, daily maximum temperatures lower than daily minimum temperatures, and any identified outliers. Daily temperature outliers were identified by manually examining visual data graphs and histograms; suspicious outliers were identified using statistical tests, local knowledge, and comparisons with adjacent days or the same day at neighboring stations. Data that was clearly flawed were adjusted or removed.

Due to relocation of meteorological stations, instrument changes, or observing procedures, step changes were identified at specific stations which resulted in observed meteorological data to not be fully comparable. To eliminate problems associated with step changes, daily temperature values were used to calculate the monthly temperatures; $\log$ transformations were subsequently used to test data 

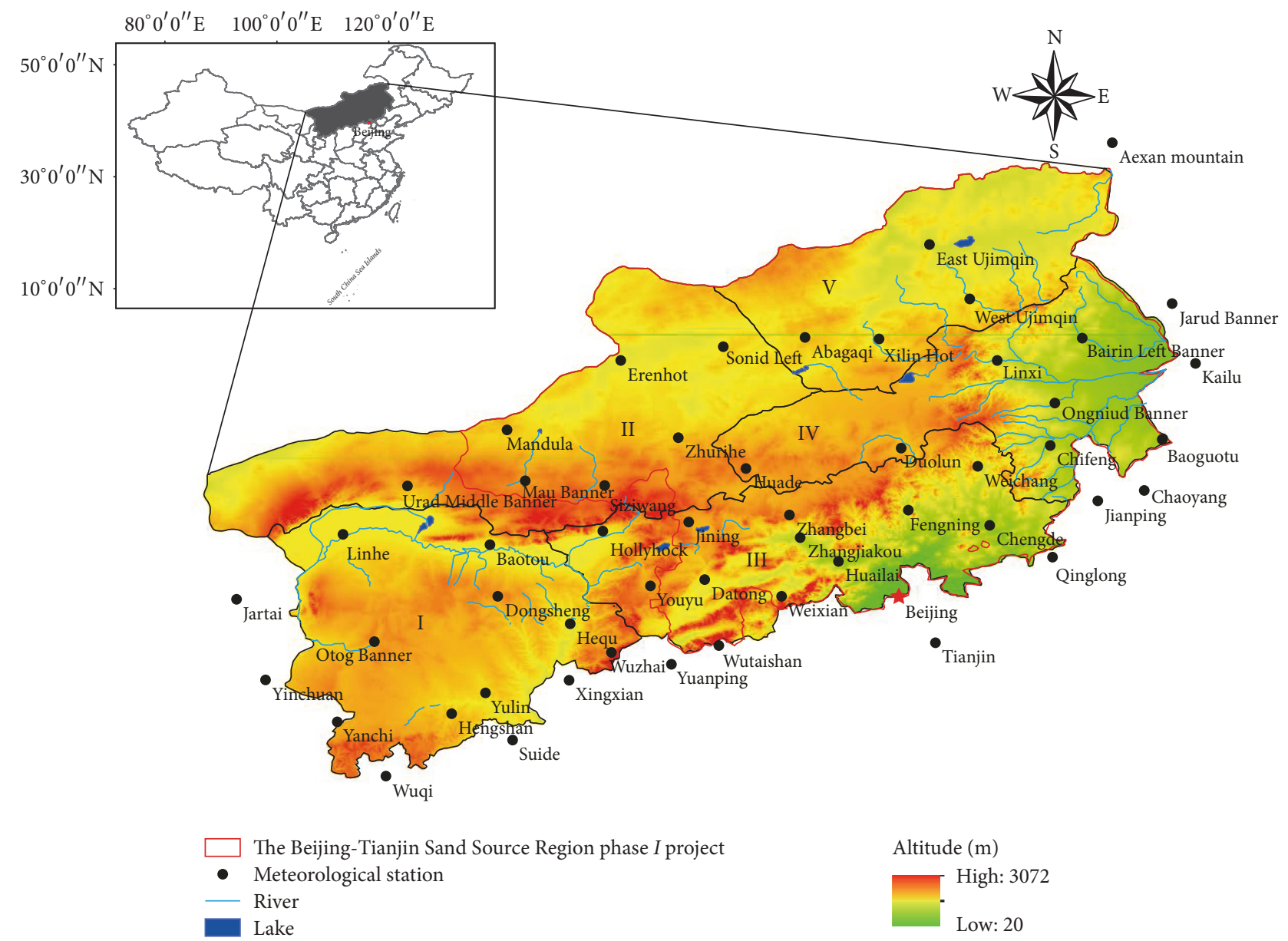

FIGURE 1: Location of the study area and meteorological stations. Greek capital numbers indicate the subregion division: I is the southwest subregion (SR-I), II is the northwest subregion (SR-II), III is the south-central subregion (SR-III), IV is the east-central subregion (SR-IV), and $\mathrm{V}$ is the northeast subregion (SR-V). Source: [27].

homogeneity using the RHtest V4 [32]. Any step changes identified using RHtest V4 were analyzed using metadata to evaluate the changes. Results from these tests showed that all data from the 53 meteorological stations were acceptable for use in this investigation.

After quality control and homogeneity tests, monthly temperature values were used to calculate mean annual temperatures, the standard climatological seasons (spring: March-May; summer: June-August; autumn: September-November; Winter: December-February) and the growing season (GS: April-October).

3.2. Calculation of Mean Temperature and Indices. To identify spatial changes in average temperature and extremes, the study region was divided into five subregions: the southeast subregion (SR-I), the northwest subregion (SR-II), the southcentral subregion (SR-III), the east-central subregion (SRIV), and the northeast subregion (SR-V), as per the investigation of $\mathrm{Lu}$ and $\mathrm{Wu}$ [27] (Figure 1). Temporally, two time cut points were determined as the starting year of reform and opening policy (ROP) (1979) and the starting year of the Blown-Sand Control Project Phase I in the BTSSR (hereafter referred to as project phase I) (2000). To identify the impact of land use/land cover on temperature and extremes, the study period (S: 1960-2014) was divided into three time stages: 1960-1978 $\left(\mathrm{S}_{1}\right)$ (prior to ROP); 1979-1999 $\left(\mathrm{S}_{2}\right)$ (ROP to before project phase I); and 2000-2014 $\left(\mathrm{S}_{3}\right)$ (Project phase I).

Ten core indices for extreme temperature from ETCCDMI, indices which have been widely applied to evaluate extreme temperature shifts [33-40], were selected and classified into three categories: cold-related indices, warm-related indices, and variability indices (Table 1). All calculations of these indices were undertaken using RClimDex 1.0 software [30].

3.3. Trend Analysis of Mean Temperature and Indices. Trends in mean temperature and indices were analyzed for the three time stages and for the duration of the study period. Trends for individual station data and regional series were estimated; the significance of the trends was determined using the Mann-Kendall test $[41,42]$. This test does not assume that data are normally distributed, and it robustly responds to the effects of outliers in the series; this test has been previously 


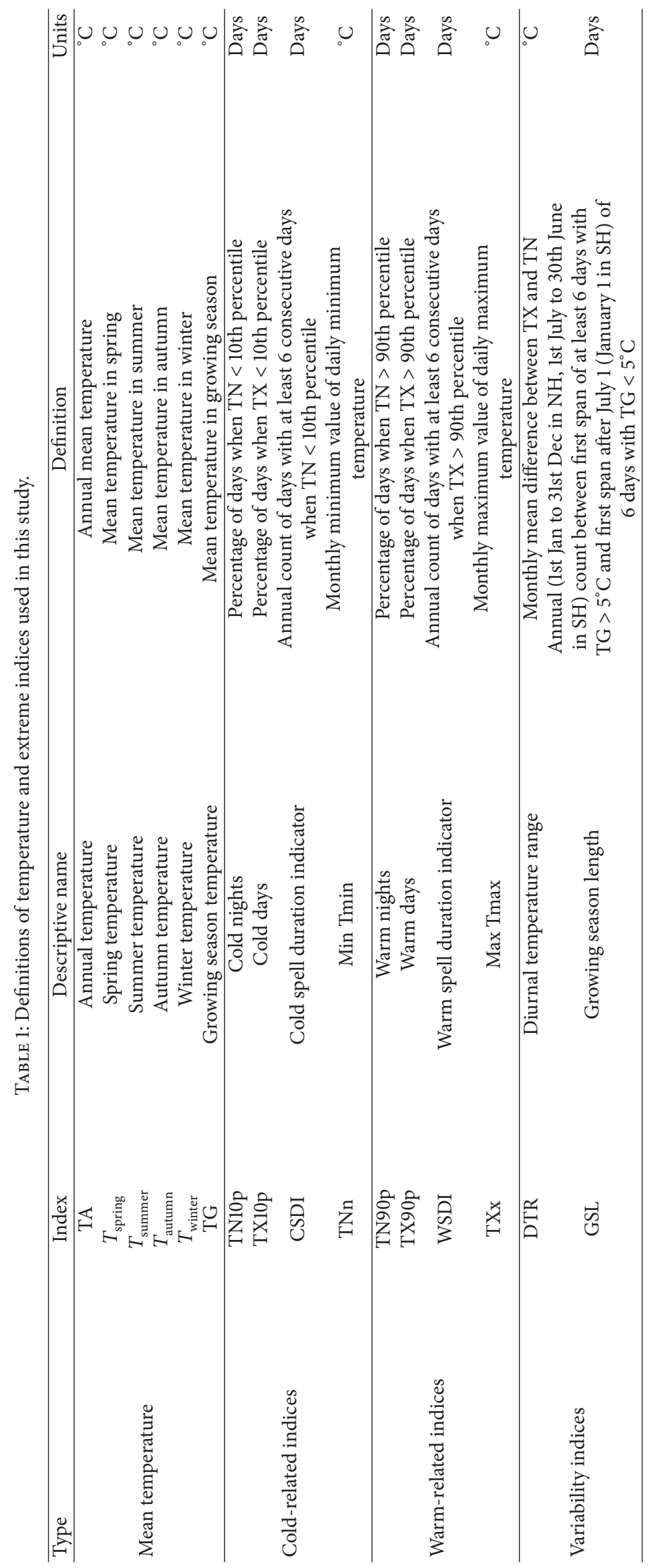




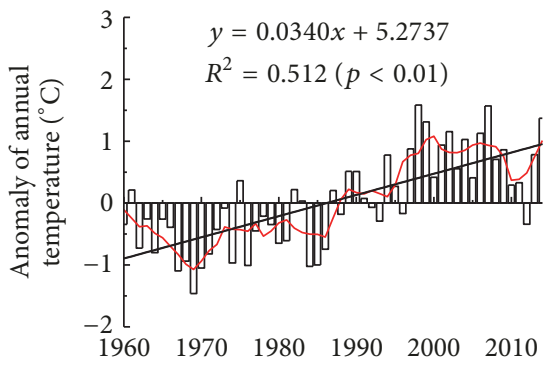

(a)

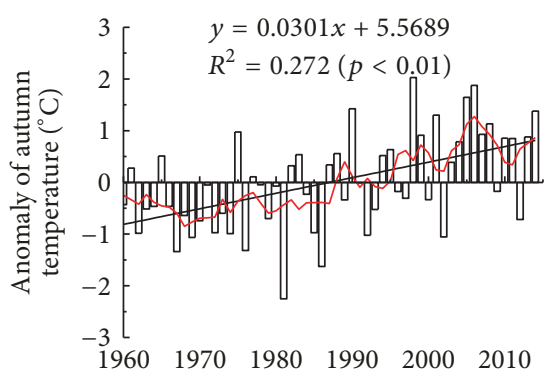

(d)

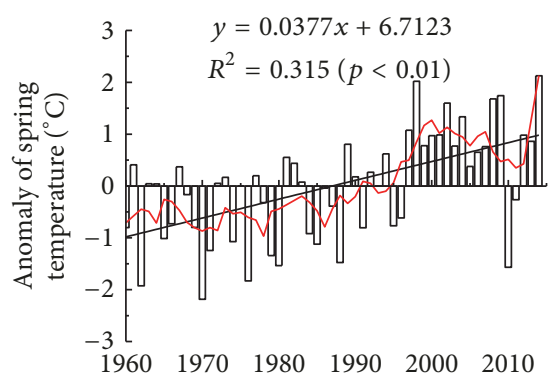

(b)

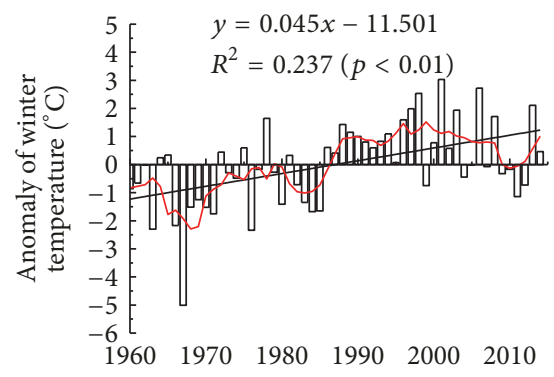

(e)

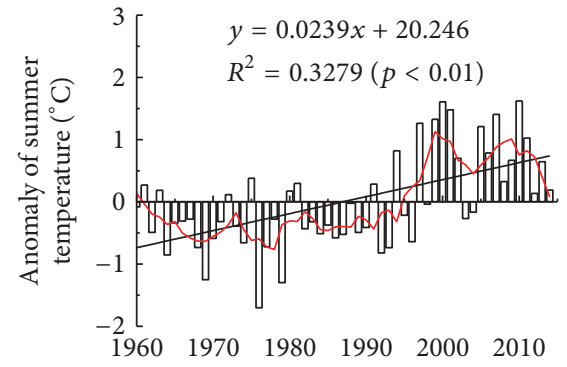

(c)

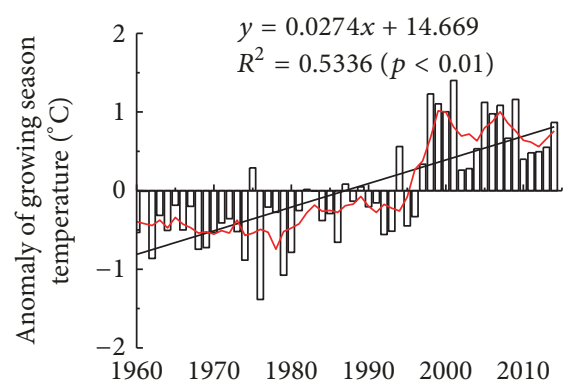

(f)

Figure 2: Anomaly of regional average temperature curves over the BTSSR, 1960-2014. The blackline represents the linear trends for (a) annual, (b) spring, (c) summer, (d) autumn, (e) winter, and (f) growing season. The redline represents the 5-year moving average.

used to test trends in hydrological and meteorological data $[26,43,44]$.

The Mann-Kendall test, enabling data with missing values and values below a detection limit to be analyzed, is one of the most important and commonly used statistical methods to detect trends as nonparametric tests in hydroclimatic time series data. The null hypothesis that $Z_{c}$ is not statistically significant or has no significant trend will be accepted if $-Z_{(1-\alpha) / 2} \leq Z_{c} \leq Z_{(1-\alpha) / 2}$, where $\pm Z_{(1-\alpha) / 2}$ are the standard normal deviates and $\alpha$ is the significance level for the test [45].

Kendall's statistic $S$ assessing the monotonic trend was calculated as

$$
\begin{aligned}
S & =\sum_{i=1}^{n-1} \sum_{k=i+1}^{n} \operatorname{sgn}\left(x_{k}-x_{i}\right) \\
\operatorname{var}(S) & =\frac{n(n-1)(2 n+5)-\sum_{i=1}^{m} e_{i}\left(e_{i}-1\right)\left(2 e_{i}+5\right)}{18},
\end{aligned}
$$

where $x_{k}$ and $x_{i}$ are sequential data values representing the annual values in years $k$ and $i$, respectively; $n$ is the time length of the dataset; $\operatorname{sgn}(\theta)=-1$ if $\theta<0, \operatorname{sgn}(\theta)=0$ if $\theta=0$, and $\operatorname{sgn}(\theta)=1$ if $\theta>0 ; e_{i}$ is the number of ties of the $i$ th value and $m$ is the number of tied values. The Mann-Kendall test statistic $Z_{c}$ was calculated as

$$
\begin{aligned}
& Z_{c}=\frac{S-1}{\sqrt{\operatorname{var}(S)}}, \quad \text { if } S>0, \\
& Z_{c}=0, \quad \text { if } S=0, \\
& Z_{c}=\frac{S+1}{\sqrt{\operatorname{var}(S)}}, \quad \text { if } S<0,
\end{aligned}
$$

where $Z_{c}$ is a standard normal variable. A positive $Z_{c}$ indicates an upward trend while a negative $Z_{c}$ indicates a downward trend [46]. A two-sided test at the significance level of 5\% was undertaken in this study, and Sen's slope estimator was used to estimate the true slope of an existing trend (the change per year) [47]. All of the trend calculations for these indices were undertaken using MAKESENS 1.0 [48]. Prior to performing the Mann-Kendall test, the trend-free, prewhitening method of Yue et al. [49] was used to limit the effect of serial correlations on the Mann-Kendall test [50, 51].

3.4. Spatial Interpolation of Mean Temperature and Extremes Trends. Mean temperature and indices trends were spatially interpolated using the spline method. This is characterized by fitting a smooth and continuous surface with the observation points, and it does not require a preliminary estimate for the structure of a temporal variance and statistical hypothesis [52]. In comparison with other methods, previous studies, for example, those using Kriging $[53,54]$ and those analyzing climatic and meteorological change [55-58], have shown the spline method to be more advantageous around topographic features. Spatial interpolation with the spline method was completed using ArcGIS software (Version 10.2).

\section{Results and Discussion}

\subsection{Mean Temperature Spatiotemporal Trends}

4.1.1. Annual Temperature. MK test results across the study period for the BTSSR show that annual temperature (TA) significantly increased $(p<0.001)$. The TA slope was $0.34^{\circ} \mathrm{C} /$ decade (Figures 2(a) and 3(a), Table 2), a result which 


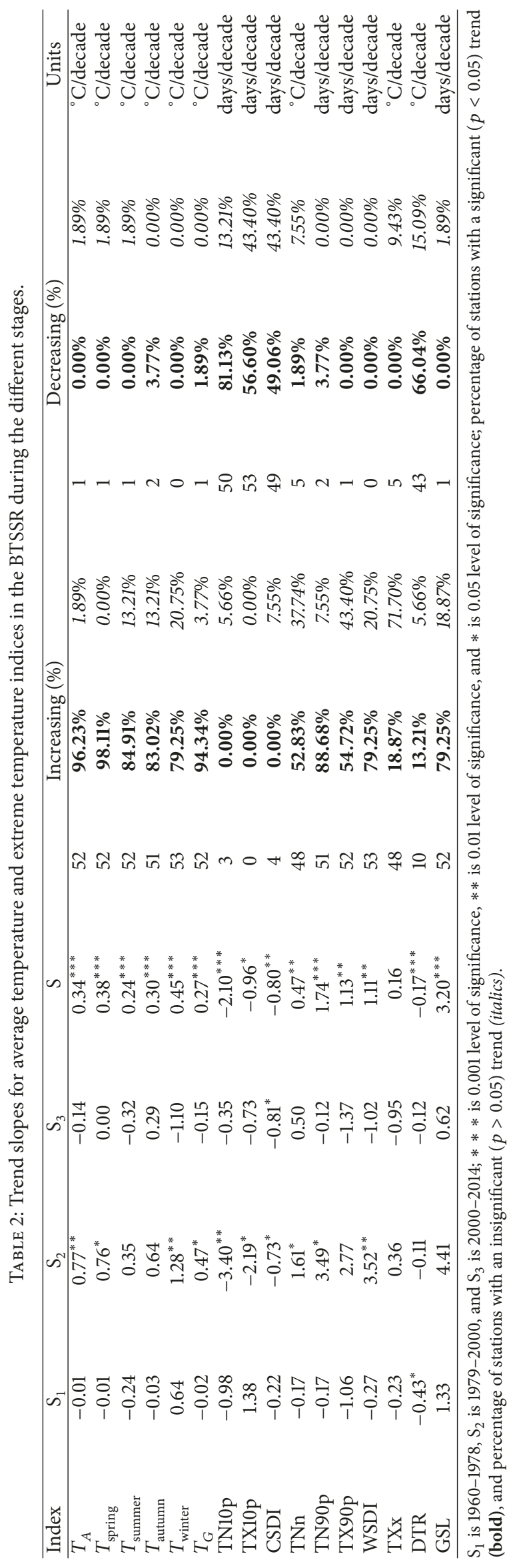




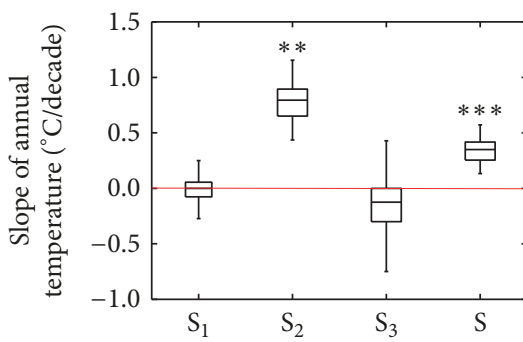

(a)

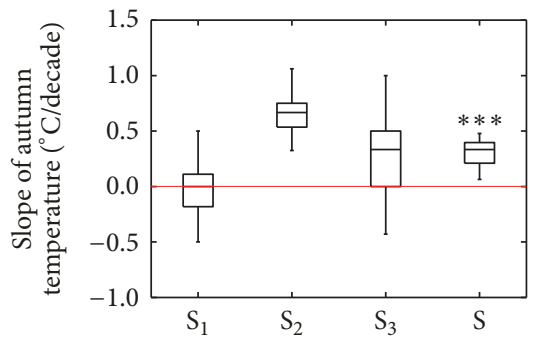

(d)

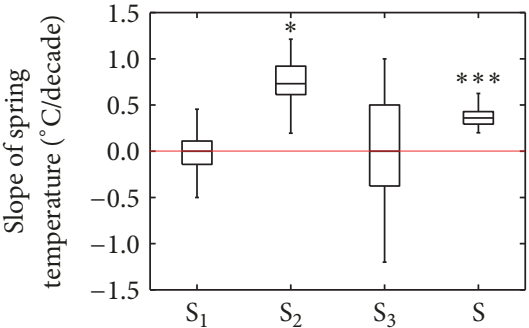

(b)

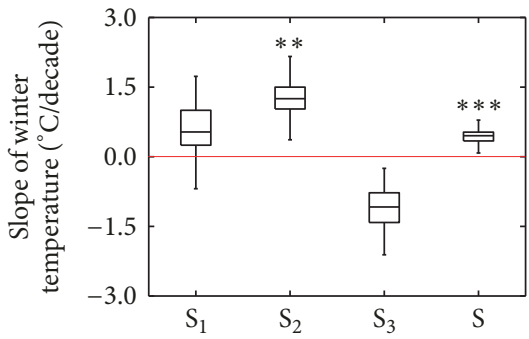

(e)

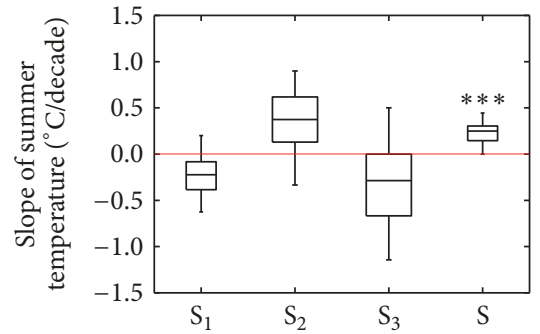

(c)

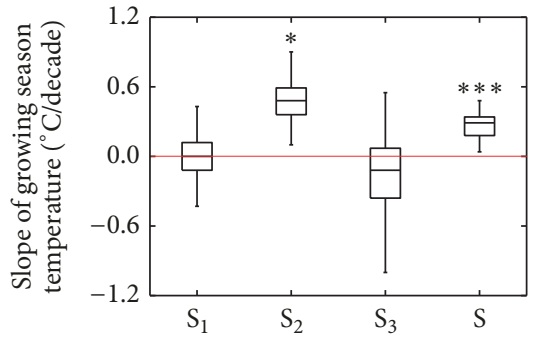

(f)

FIGURE 3: Box-Plot of Slopes for regional average temperature over the BTSSR in different stages. (a) Annual, (b) spring, (c) summer, (d) autumn, (e) winter, and (f) growing season. $S_{1}$ is $1960-1978, S_{2}$ is $1979-2000, S_{3}$ is $2000-2014$, and $S$ is $1960-2014$. * * * is 0.001 level of significance, $* *$ is 0.01 level of significance, and $*$ is 0.05 level of significance.

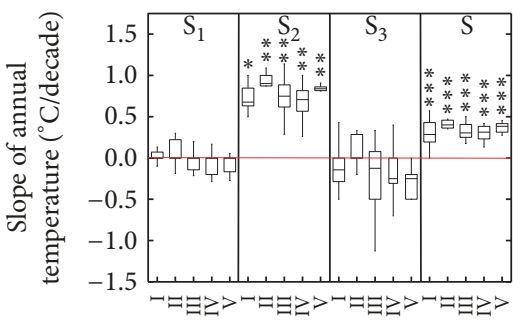

(a)

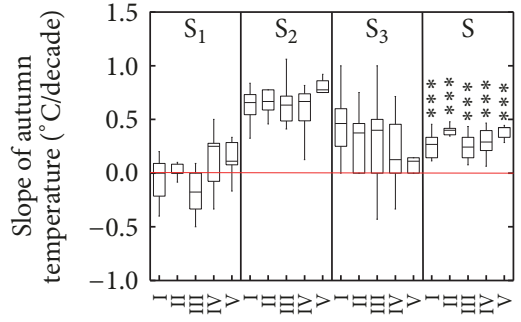

(d)

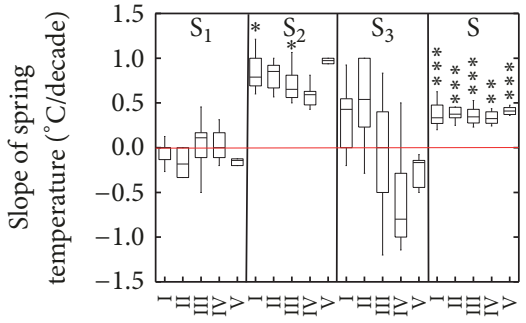

(b)

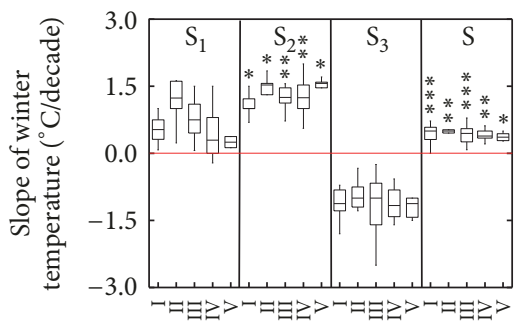

(e)

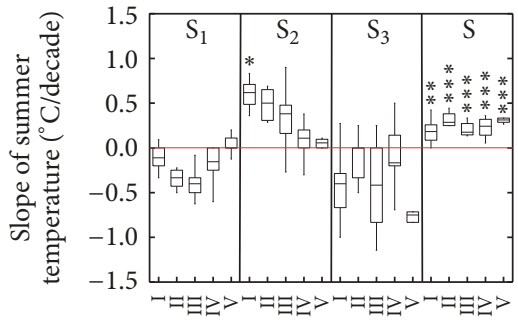

(c)

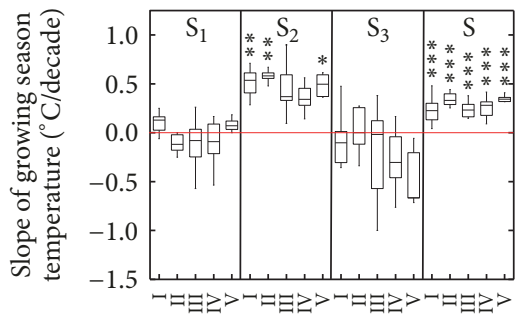

(f)

FIGURE 4: Box-Plot of Slopes for regional average temperature over the five subregions in different stages. (a) Annual, (b) spring, (c) summer, (d) autumn, (e) winter, and (f) growing season. $S_{1}$ is 1960-1978, $S_{2}$ is 1979-2000, $S_{3}$ is 2000-2014, and $S$ is 1960-2014. I is the southwest subregion (SR-I), II is the northwest subregion (SR-II), III is the south-central subregion (SR-III), IV is the east-central subregion (SR-IV), and $\mathrm{V}$ is the northeast subregion (SR-V). $* * *$ is 0.001 level of significance, $* *$ is 0.01 level of significance, and $*$ is 0.05 level of significance.

coincides with TA change trends identified in the China territory $[59,60]$, in regions such as the Yellow River basin, the Yangtze River Basin [61], arid and semiarid regions in northwest China [62], and those in the monsoon area of eastern China [63]. TA results for the different stages showed some differences to those recorded for the entire study period. TA recorded a slightly downward trend in $\mathrm{S}_{1}$, a significantly upward trend in $\mathrm{S}_{2}$ (with a slope of $0.77^{\circ} \mathrm{C} /$ decade), and an insignificant downward trend in $S_{3}$ (Figure 3(a), Table 2), results which may be due to alternating surface albedo due to large areas of desertification in $S_{2}$ and rapid revegetation activities in $\mathrm{S}_{3}[23,37,64-70]$.

The variations in $T_{A}$ trends for the different stages in the five subregions are shown in Figure 4(a) and Table 3. Results show that $T_{A}$ trends in these subregions significantly increased from 1960 to 2014 ( $p<0.001$ ); the highest $T_{A}$ 


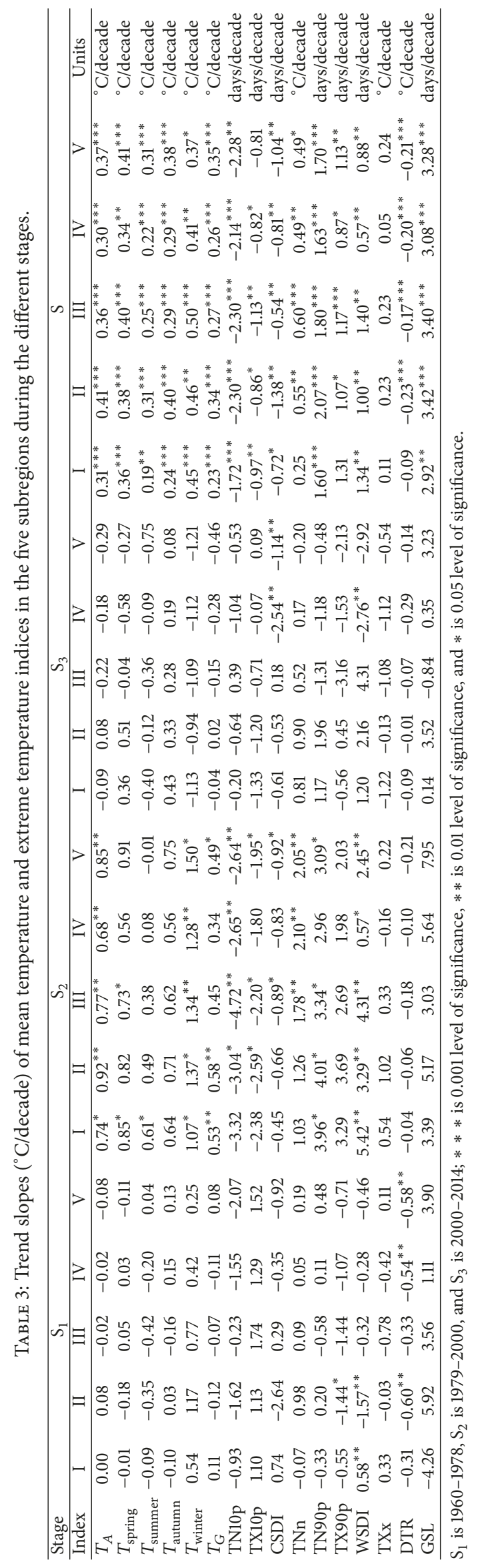


slope was $0.41^{\circ} \mathrm{C} /$ decade in the northwest subregion (SR-II) while the east-central subregion (SR-IV) recorded the lowest slope $\left(0.30^{\circ} \mathrm{C} /\right.$ decade) (Figures 3(a) and 4(a), Table 3). Results for all five subregions recorded a slight fluctuation during $\mathrm{S}_{1}$ and a significant increasing trend in $\mathrm{S}_{2}$, especially in the northwest subregion (SR-II; $0.92^{\circ} \mathrm{C} /$ decade), a result which may be attributed to serious steppe degradation in this area $[71,72]$. During the last decade, $T_{A}$ recorded slightly negative trends, except for the northwest subregion (SR-II).

Results for the spatial distribution of $T_{A}$ trends (Figure 5(a)) show that most areas of the BTSSR had positive slopes, with the largest occurring in the central-southern mountain area; however, negative slopes were identified in the southeastern region in the Luanhe River Basin. Based on data from 51 stations ( $96.23 \%$ of all stations), the spatial distribution of $T_{A}$ showed a significant increase in the BTSSR $(p<0.01)$ (Table 2), corresponding to the average slope of $0.35^{\circ} \mathrm{C} /$ decade. A strong increasing trend was observed at the Wutaishan station and a weak negative trend was found at the Chengde station, both meteorological stations being situated in the south-central subregion (SR-III).

In general, an increasing $T_{A}$ trend in the BTSSR can accelerate plant growth by altering plant photosynthesis processes $[73,74]$ and lengthening the growing season $[75,76]$. However, increasing $T_{A}$ trends can also increase regional evapotranspiration [26] which, in conjunction with a decreasing trend in precipitation in the BTSSR [77], will increase the risk of drought [78]. The tradeoff of change trends of these meteorological factors is currently unclear.

4.1.2. Seasonal Temperature. MK test results indicate that the seasonal temperature of the BTSSR significantly increased $(p<0.05)$ during the study period; the lowest $\left(0.24^{\circ} \mathrm{C} /\right.$ decade $)$ and highest $\left(0.45^{\circ} \mathrm{C} /\right.$ decade $)$ rate of temperature rise were recorded in summer and winter, respectively (Figures 2(b)-2(e) and 3(b)-3(e), Table 2). This result was similar to that recorded by Wang et al. [79] for seasonal temperature changes across the arid region of northwestern China. Results for the different stages of the BTSSR showed differing changes. Results during $S_{1}$ recorded seasonal temperature to have a slightly negative trend, except for winter temperature $\left(T_{\text {winter }}\right)$. Seasonal temperature in $\mathrm{S}_{2}$ increased, with $T_{\text {winter }}$ recording a significant increase (having a slope of $1.28^{\circ} \mathrm{C} /$ decade) and $T_{\text {summer }}$ having an insignificant increase (with a slope of $0.35^{\circ} \mathrm{C} /$ decade), results which were in agreement with seasonal temperature changes across northeastern China [80]. Seasonal temperatures during $\mathrm{S}_{3}$ recorded a mixture of slightly negative and positive trends (Table 2).

Results for seasonal temperature trends across the five subregions (Figures 4(b)-4(e), Table 3 ) recorded a significant increase $(p<0.05)$ during the study period, especially for $T_{\text {winter }}$ in SR-III (having a slope of $0.50^{\circ} \mathrm{C} /$ decade) (Figures $5(\mathrm{~b})-5(\mathrm{e})$ ). During $\mathrm{S}_{1}$, insignificant increasing trends for $T_{\text {winter }}$ were recorded in all subregions, while other seasonal temperature series showed a mixture of slightly negative and positive trends across the five subregions. During $\mathrm{S}_{2}$, $T_{\text {winter }}$ showed a significant increasing trend in all subregions, especially in SR-V (with a slope of $1.50^{\circ} \mathrm{C} /$ decade), and other seasonal temperature series showed insignificant positive trends for most subregions. Insignificant decreasing trends were recorded in the five subregions during the winter months and summer months, while spring temperatures showed a mixture of slightly negative and positive trends, with more negative than positive trends being recorded, and slightly increasing trends were found in all five subregions during the autumn months over the last decade (Figures 4(b)-4(e), Table 3 ).

The spatial distribution of seasonal temperature trends (Figures 5(b)-5(e)) shows that a positive temperature slope was identified for almost the entire BTSSR in the four seasons; the southeastern area of SR-III and the eastern area of SR-I were exceptions, these areas recording negative $T_{\text {spring }}, T_{\text {summer }}$, and $T_{\text {autumn }}$ slopes and a negative $T_{\text {autum }}$ slope, respectively (Figures $5(\mathrm{~b})-5(\mathrm{e})$ ). Most stations exhibited increasing trends, with the lowest winter slope of $0.01^{\circ} \mathrm{C} /$ decade (Hequ station) and the highest winter slope of $1.51^{\circ} \mathrm{C} /$ decade (Wutaishan station) being located in SR-I and SR-III, respectively. In spring, data from $98.11 \%$ of stations recorded a significant increasing trend (Figure 5(b), Table 2). In summer and autumn, the number of stations recording significant positive trends was similar, the trends mainly occurring in SR-I, SR-III, and SR-IV. Similarly, the number of stations recording negative trends was few (Figures 5(c) and 5(d), Table 2). In the winter, 42 stations recorded significant positive trends (79.25\% of all stations), these being mainly located in SR-I, SR-III, and SR-IV, with no station recording a negative trend (Figure 5(e), Table 2). This result implies that the southern and east-central areas of the BTSSR experienced a warmer climate each year.

The winter warming trends identified in our study across the BTSSR are similar to those previously identified in Europe [81], North Asia and North America [82], subarctic [83], China $[84,85]$, and other areas across the globe [86]. Winter warming will undoubtedly be beneficial in alleviating vegetation damage due to freezing temperatures, to both native and planted vegetation, and it will increase the possibility of using low cold-tolerant plants to revegetate the BTSSR.

4.1.3. Growing Season Temperature. MK test results for growing season temperature $\left(T_{G}\right)$ from 1960 to 2014 across the BTSSR recorded a significant increase $(p<0.001)$, with a slope of $0.27^{\circ} \mathrm{C} /$ decade (Figures 2(f) and 3(f), Table 2). Results during the different stages showed $T_{G}$ to record a slight decrease in $S_{1}$, a significant increase in $S_{2}$ (with a slope of $0.47^{\circ} \mathrm{C} /$ decade), and an insignificant decline in $S_{3}$ (Figure 3(f), Table 2). The overall trend of $T_{G}$ was similar with that of $T_{A}$.

Results for the variations in $T_{G}$ trends for the five subregions in the different stages recorded a significant increase $(p<0.001$; Figure 4(f), Table 3) from 1960 to 2014, especially in SR-V, with a slope of $0.35^{\circ} \mathrm{C} /$ decade (Figures $5(\mathrm{f})$ and $4(\mathrm{f}$ ), Table 3). As temperatures increased, the date of initiation of the growing season advanced and earlier growth resulted in vegetation covering the land earlier, thus reducing the occurrence of dust storms [87]. However, earlier vegetation growth could increase water stress in the reproductive growth period of water-limited vegetation in the BTSSR [24]. $T_{G}$ 


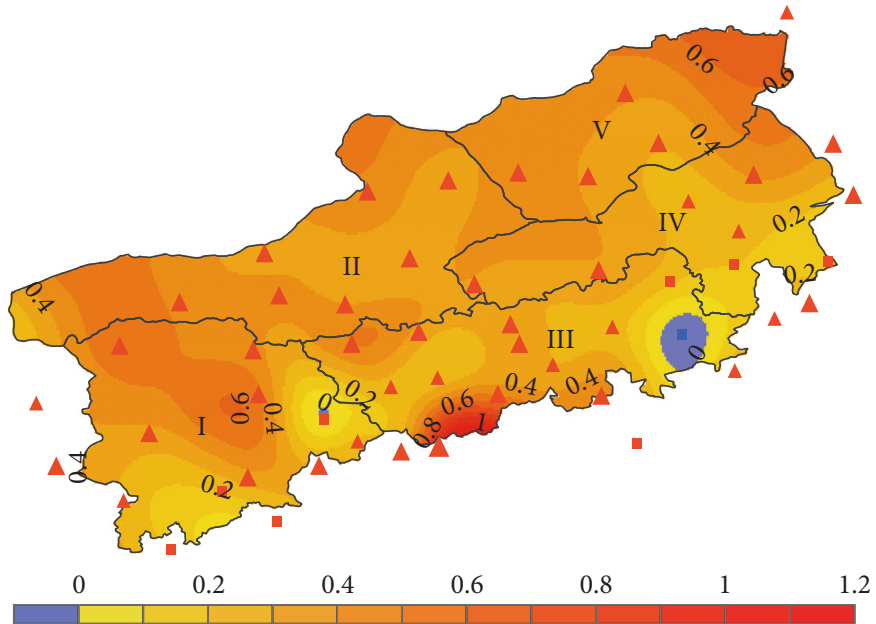

Annual temperature $\left({ }^{\circ} \mathrm{C} /\right.$ decade $)$

- $-0.07-0.00 \quad \Delta \quad 0.31-0.57$

- $0.00-0.21 \quad 0.57-1.17$

a $0.21-0.31$
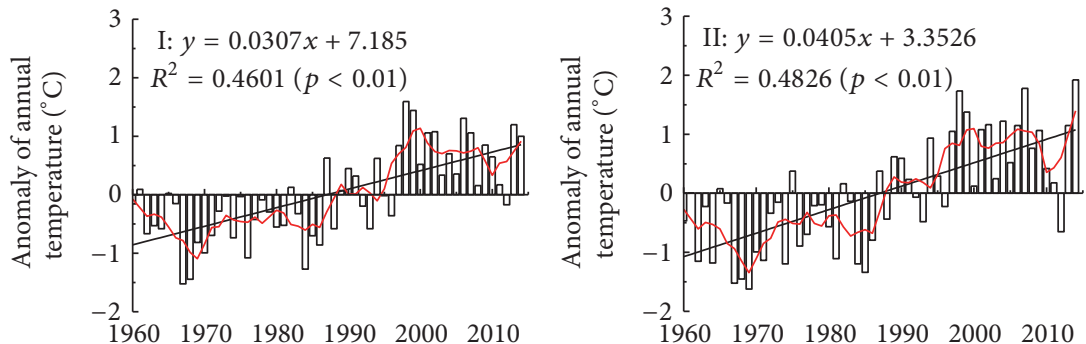

(a)

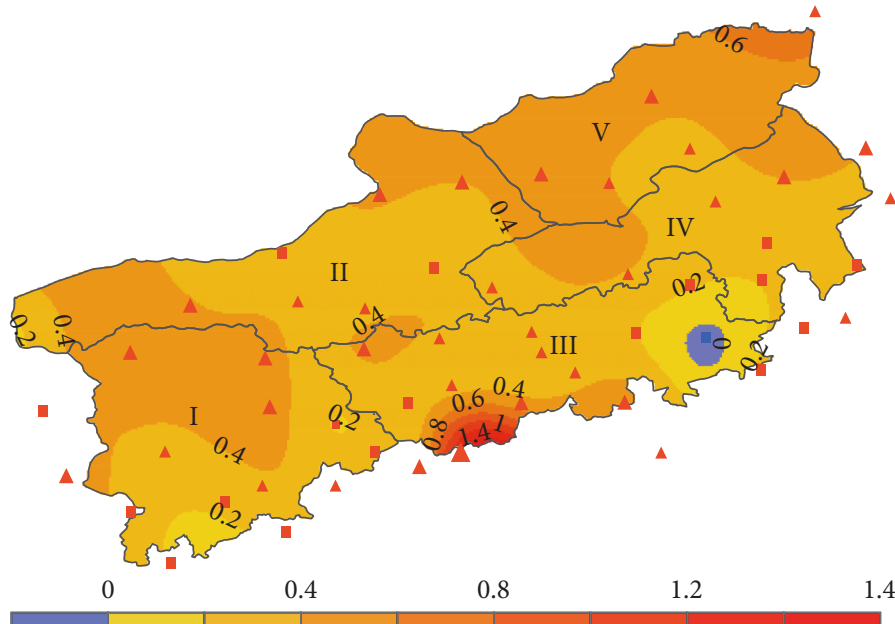

Spring temperature $\left({ }^{\circ} \mathrm{C} /\right.$ decade $)$

- $-0.04-0.00$ ॥ $0.41-0.59$

- $0.00-0.31 \quad \Delta \quad 0.59-1.49$

A $0.31-0.41$
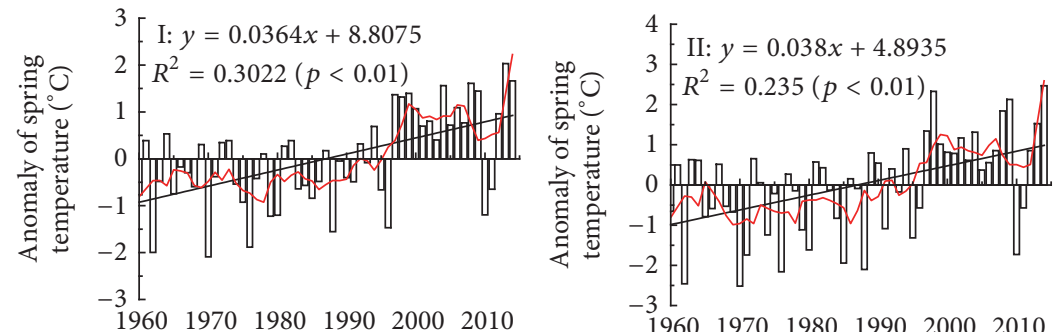

(b)
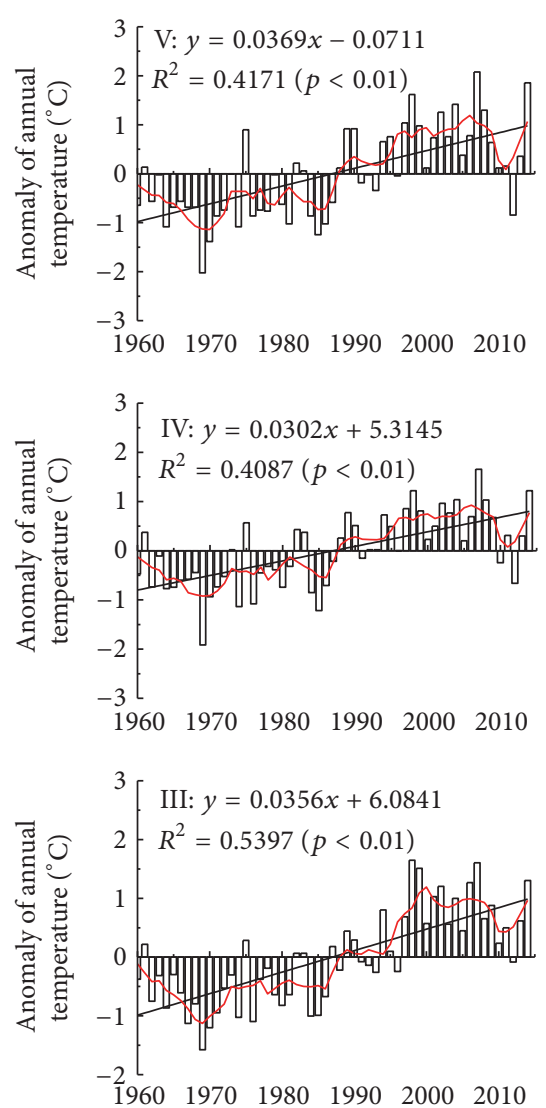
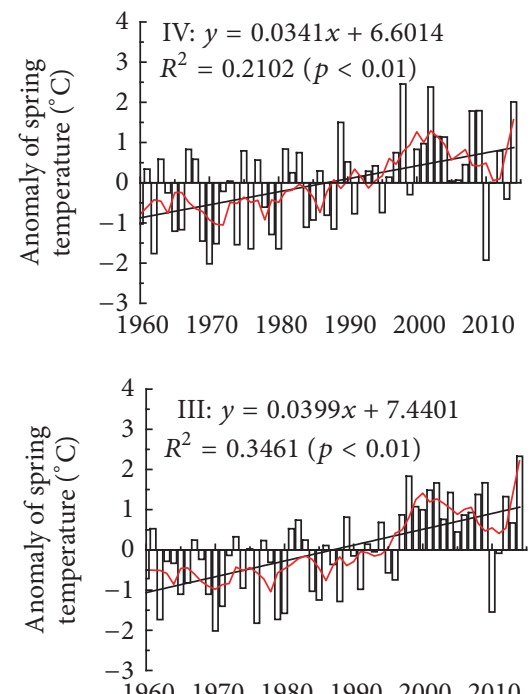

$\begin{array}{llllll}960 & 1970 & 1980 & 1990 & 2000 & 2010\end{array}$

Figure 5: Continued. 


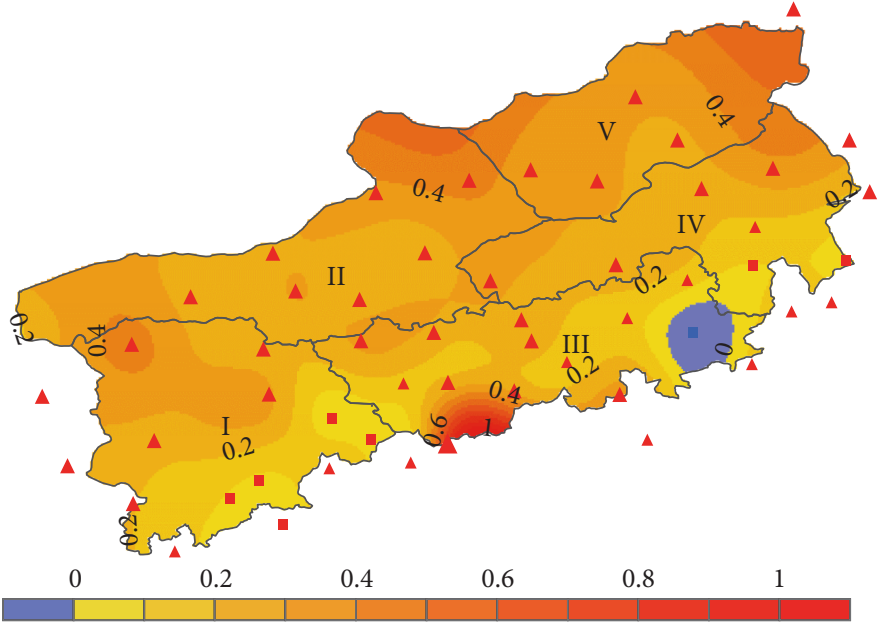

Summer temperature $\left({ }^{\circ} \mathrm{C} /\right.$ decade $)$

- $-0.10-0.00 \quad \Delta \quad 0.21-0.45$

- $0.00-0.14 \quad 0.45-1.07$

$\triangle 0.14-0.21$
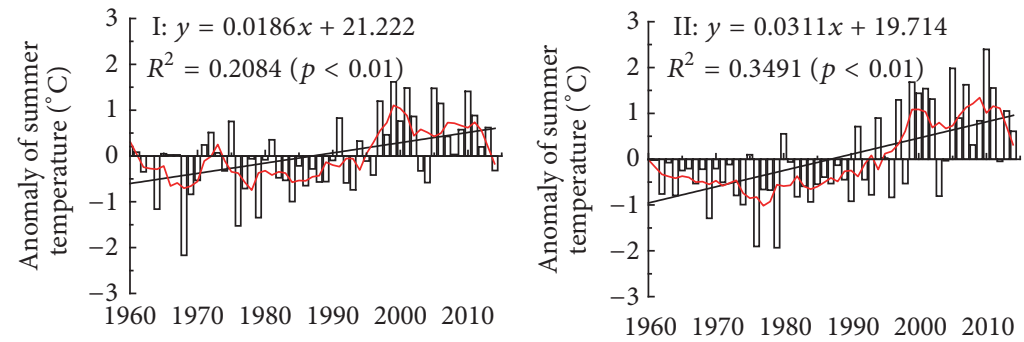

(c)

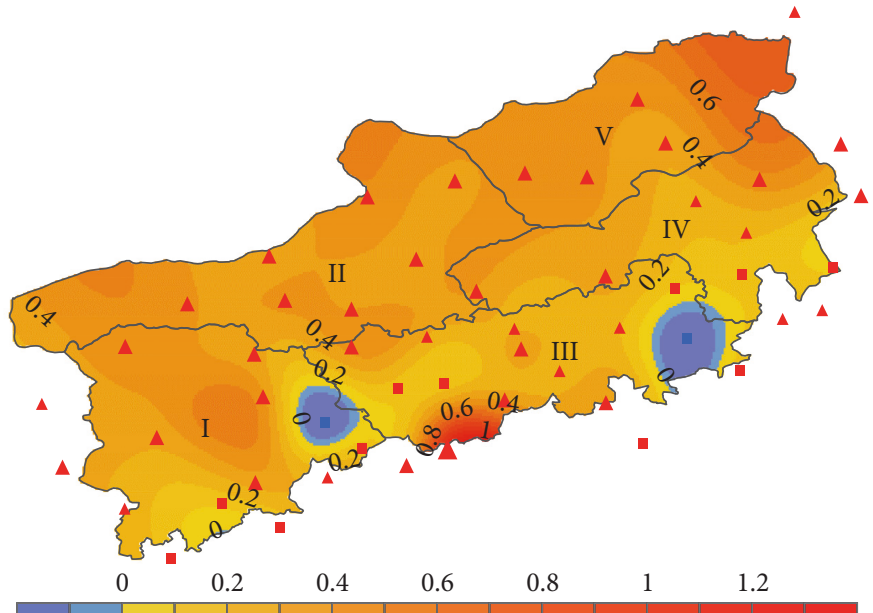

Autumn temperature $\left({ }^{\circ} \mathrm{C} /\right.$ decade $)$

- $-0.18-0.00 \quad \Delta \quad 0.31-0.48$

- $0.00-0.21 \quad \Delta \quad 0.48-1.27$

A $0.21-0.31$
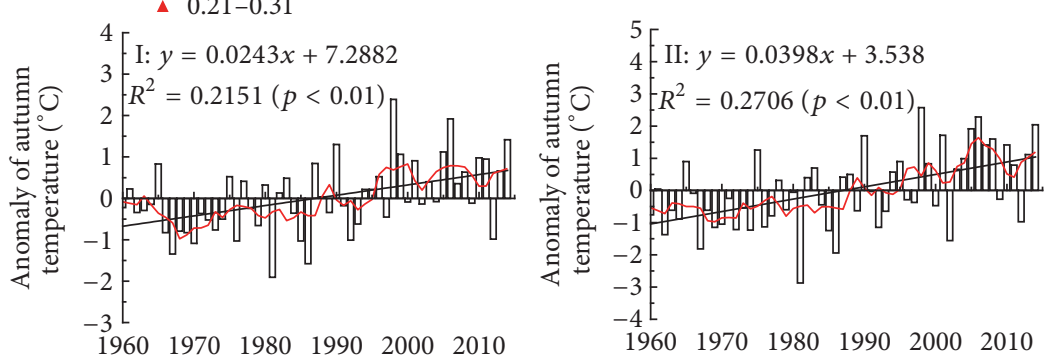

(d)
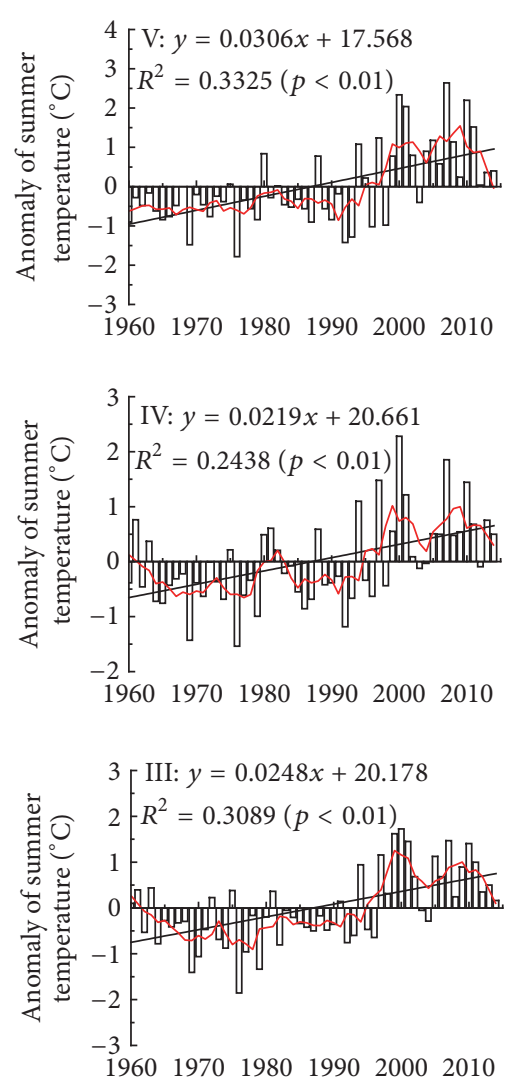
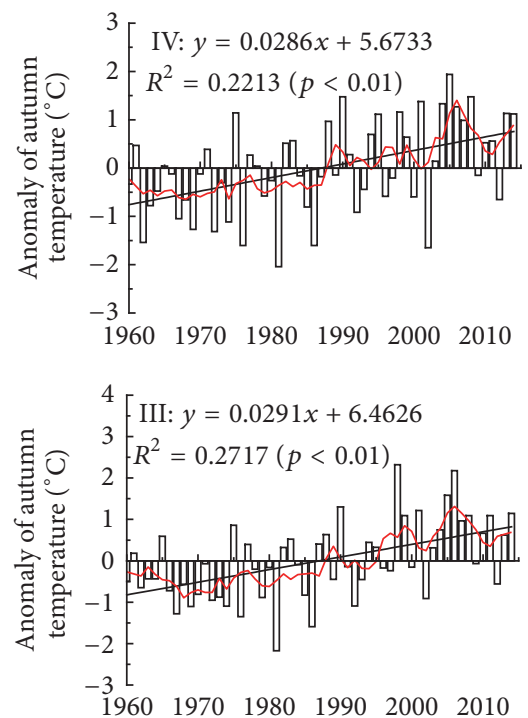

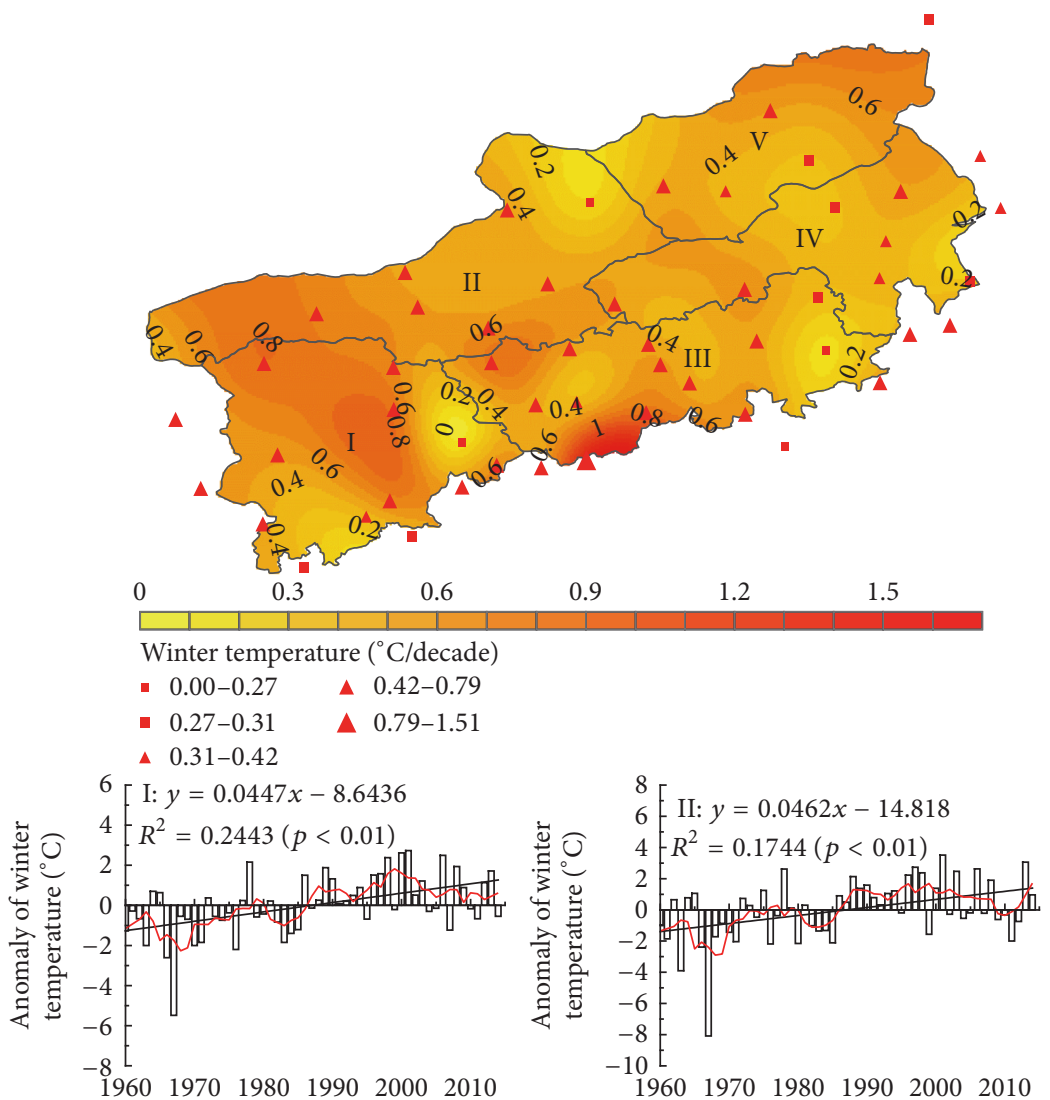

(e)
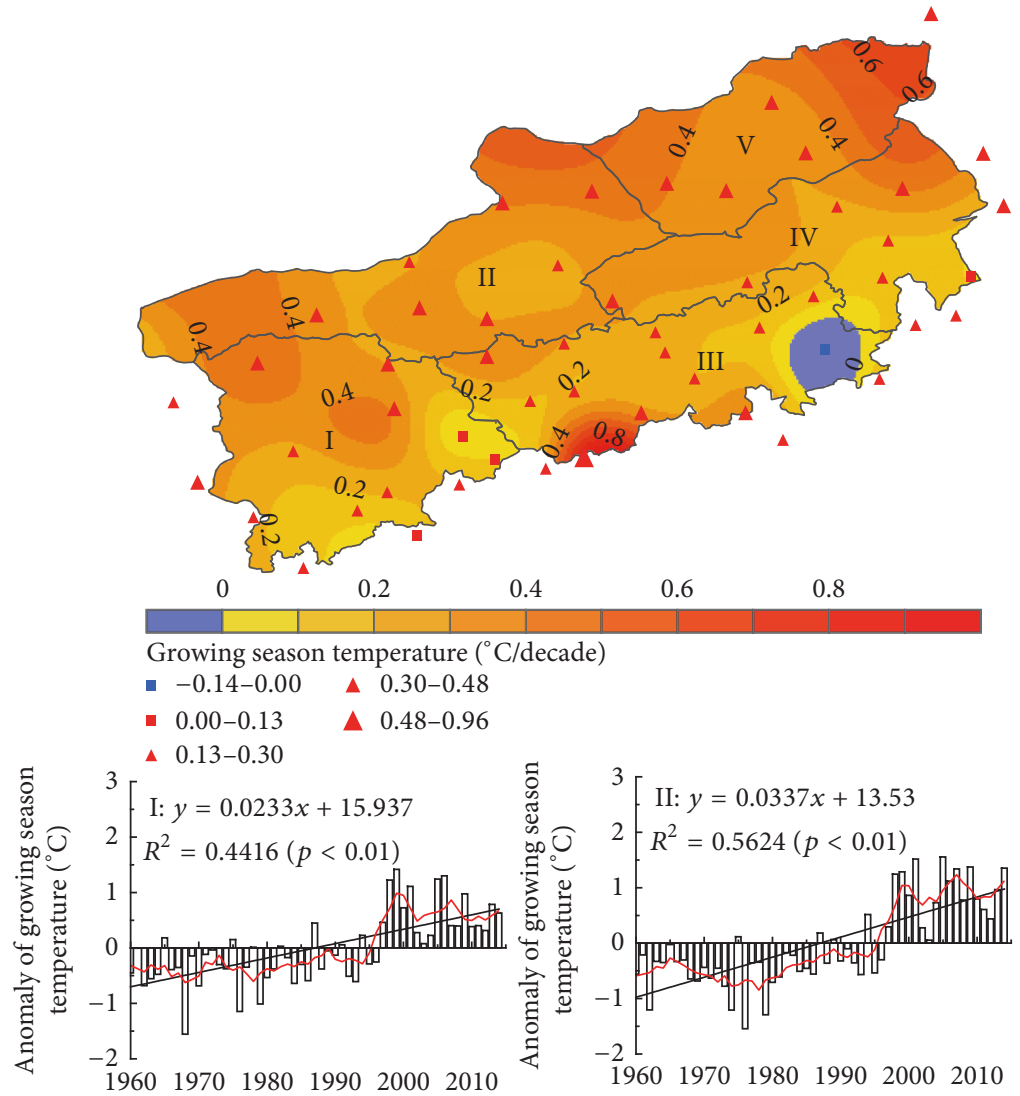
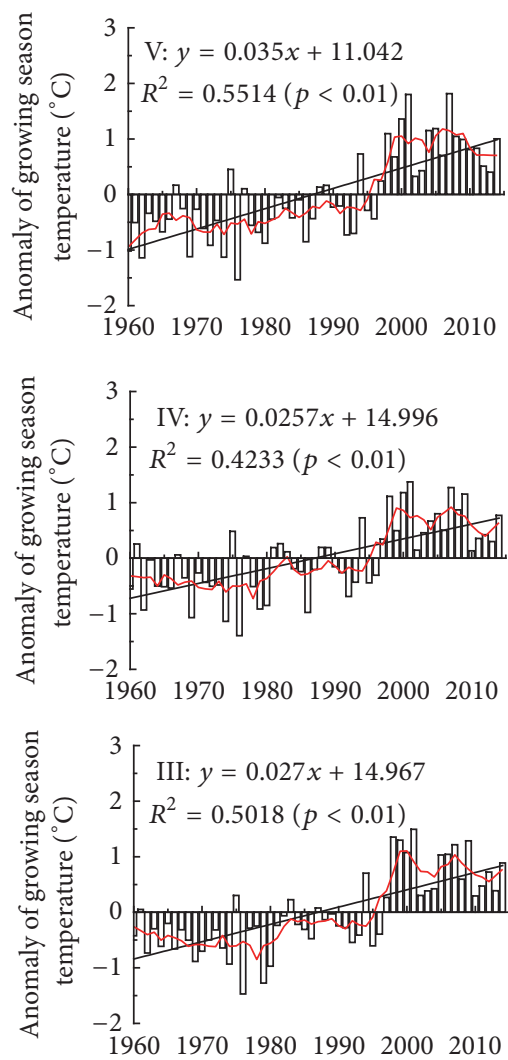

(f)

FIGURE 5: Spatial patterns of the trend slopes of mean temperature (1960-2014) over the BTSSR and anomaly of subregional indices curves. The blackline represents linear trends for (a) annual, (b) spring, (c) summer, (d) autumn, (e) winter, and (f) growing season. The redline represents the 5 -year moving average. 
trends for all five subregions recorded slight fluctuations during $S_{1}$. During $S_{2}$, a slope of $0.58^{\circ} \mathrm{C} /$ decade was recorded, indicating a significant increasing trend, especially in SR-II. This result was consistent with previous findings showing $T_{G}$ to have significantly increased across most regions of China since 1980 [88]. During the last decade $\left(S_{3}\right), T_{G}$ showed slightly negative trends, except in SR-II (Figure 4(f), Table 3).

Results for the $T_{G}$ slope showed a similar spatial pattern with those for $T_{A}$ (Figure 5(f)). A larger positive slope was recorded in the central-southern mountain area and the northeast region, and a negative slope occurred in the southeastern area of SR-III. Based on data from 50 stations (94.34\% of all stations; Table 2), the spatial distribution of $T_{G}$ showed a significant increase over the BTSSR $(p<$ 0.05 ) (Figure 5(f)), corresponding to an average slope of $0.29^{\circ} \mathrm{C} /$ decade. A strong increasing trend was observed at the Wutaishan station and a significant negative trend was only found at the Chengde station, both stations being located in SR-III (Figure 5(f)).

Our results showed that a trend of increasing $T_{G}$ can enhance plant photosynthetic activities and further productivity without causing water stress [89, 90]. However, in water-limited areas of the BTSSR, increasing temperature in the growing season may exacerbate rain-fed plant stress due to high temperatures combined with decreasing precipitation $[77,91]$, especially for vegetation planted (shrubs or trees) as part of the degraded land restoration project in the BTSSR.

\subsection{Spatiotemporal Trends of Indices}

4.2.1. Cold-Related Indices. Results for temporal variation of cold nights (TN10p), cold days (TX10p), and cold spell duration indicator (CSDI), representing the frequency and duration of extreme low temperature for the BTSSR, are shown in Figures 6(a)-6(c). In general, from 1960 to 2014, the fluctuations of these indices continuously significantly decreased ( $p<0.05$ ), especially TN10p (having a slope of -2.10 days/decade; Figure 7(a), Table 2). Changes observed for TN10p are more significant than those of TX10p across the BTSSR (Figures 7(a) and 7(b), Table 2); a reduction in TN10p will result in a reduction in frost damage during the night $[92,93]$. The results of our study were in accordance with those over the arid region of northwestern China [79] and in Iran [94]. Results for the different stages showed that, during $S_{1}$, the frequency and duration of extreme low temperature recorded a slightly negative trend, except for TX10p. During $\mathrm{S}_{2}$, the frequency and duration of extreme low temperatures significantly decreased, especially TN10p (with a slope of -3.40 days/decade), and results during $\mathrm{S}_{3}$ showed CSDI to significantly decrease (a slope of -0.81 days/decade), while TN10p and TX10p insignificantly decreased (Figures 7(a)-7(c), Table 2). Figure 6(d) shows the temporal variation of Min Tmin (TNn) across the BTSSR. From 1960 to 2014, the fluctuations of TNn continuously significantly increased, having a slope of $0.47^{\circ} \mathrm{C} /$ decade $(p<0.01)$. During the different stages, TNn showed a slightly positive trend during $\mathrm{S}_{1}$, a significant increase in $\mathrm{S}_{2}$ (with a slope of $1.61^{\circ} \mathrm{C} /$ decade), and an insignificant increased in $S_{3}$ (Figure 7(d), Table 2).
Variations in the trends for the extreme cold indices at the different stages in the five subregions (Figures $8(a)-8(d)$, Table 3) show that their frequency and duration for the majority of the subregions significantly decreased from 1960 to $2014(p<0.05)$. TN10p results in SR-III recording a slope of -2.30 days/decade (Figures 8 (a) and 9(a), Table 3) and, for the majority of subregions, TNn significantly increased during the study period ( $p<0.05$ ), notably in SR-III (with a slope of $0.60^{\circ} \mathrm{C} /$ decade, Figures $8(\mathrm{~d})$ and $9(\mathrm{~d})$, Table 3 ). During the period $S_{1}$, all subregions showed a mixture of negative and positive trends, except for TN10p and TX10p. These fluctuating trends stabilized during $\mathrm{S}_{2}$ as a significant warming trend occurred, especially for TN10p in SR-III (with a slope of -4.72 days/decade), and for TNn in SRIV (with a slope of $2.10^{\circ} \mathrm{C} /$ decade), these results being in accordance with observations over China during 1979-1999 [95]. During $S_{3}$, TN10p, TX10p, and CSDI showed negative trends for most subregions while TNn showed a positive trend for most subregions, especially in SR-II (with a slope of $-0.90^{\circ} \mathrm{C} /$ decade) .

The slope distribution of TN10p showed a spatial disparity across the BTSSR (Figure 9(a)). A positive slope was identified in the eastern area of SR-I, the northern area of SR-II, and the southeastern area of SR-III, this being the area around the Chengde station; a negative slope prevailed across the rest of the region where higher negative slopes occurred along the northeast border and northwest border and in the southcentral part. Results for the spatial distribution of TN10p, based on data from 43 stations ( $81.13 \%$ of all stations), showed a significant decrease across the BTSSR $(p<0.05)$ (Table 2$)$, corresponding to an average slope of -5.05 days/decade. A strong decreasing trend was observed at the Wutaishan station in SR-III and a weak positive trend was identified at the Sonid Left station (SR-II; Figure 9(a)).

A negative slope for TX10p was identified across the entire region, with the largest slope occurring in the centralsouthern mountain area and in the east Siramulen River Basin (Figure 9(b)). Data from $56.60 \%$ of stations recorded a significant decreasing trend $(p<0.05)$ with no stations recording an increasing trend (Table 2). The Wutaishan station in SR-III recorded the strongest decreasing trend in the BTSSR (Figure 9(b)).

Results for CSDI also recorded a negative slope across the majority of the region, an exception being in the eastern parts of SR-I and SR-III where positive slopes occurred (Figure 9(c)). Data from $49.06 \%$ of stations recorded a significant decreasing trend, concentrated in the northern part of the study area (Figure 9(c), Table 2); a strong decreasing trend was observed at the Linhe station (SR-I) and a weak positive trend was identified at the Yuanping station (SR-III; Figure 9(c)).

The slopes for TNn and TN10p recorded similar patterns (Figure 9(d)), with larger positive slopes being recorded along the northeast-northwest border and in the south-central part, and negative slopes in the eastern and southern areas of SRI, the northern area of SR-II, and the eastern area of SRIII. Based on data from 28 stations $(52.83 \%$ of all stations; Table 2), the spatial distribution of TNn showed a significant increase across the BTSSR $(p<0.05)$, corresponding to an 


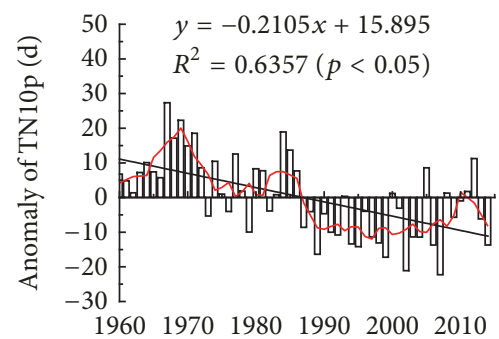

(a)

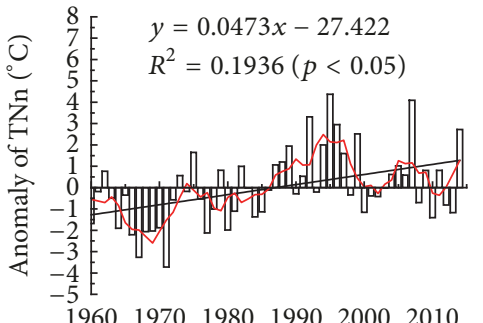

(d)

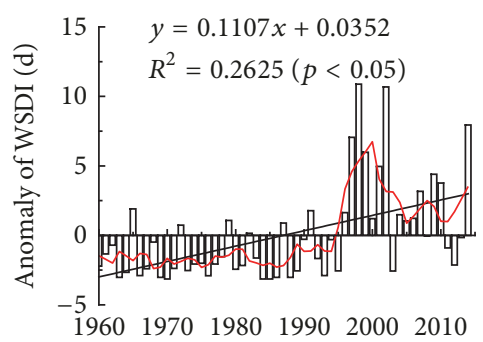

(g)

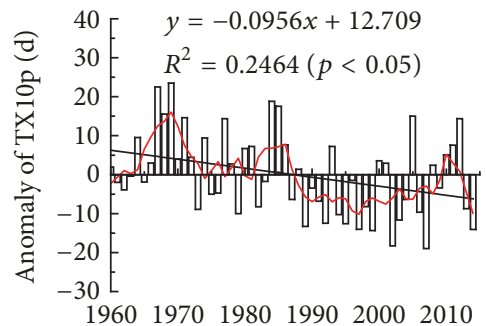

(b)

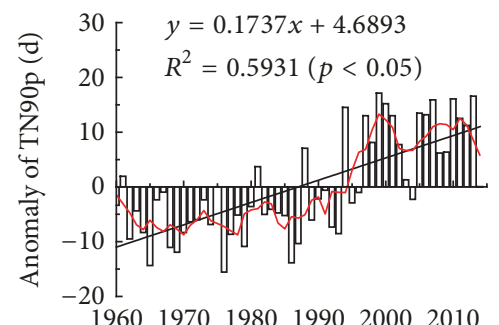

(e)

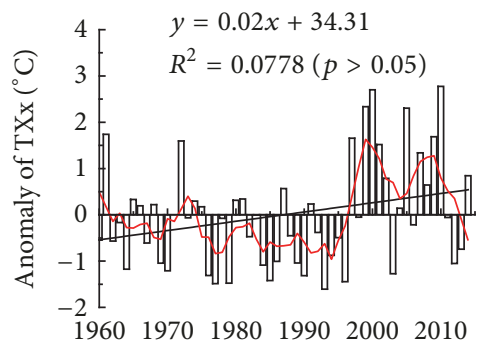

(h)

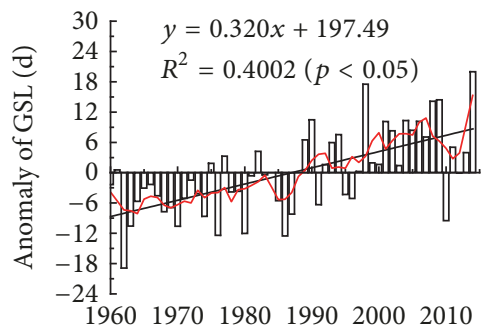

(j)

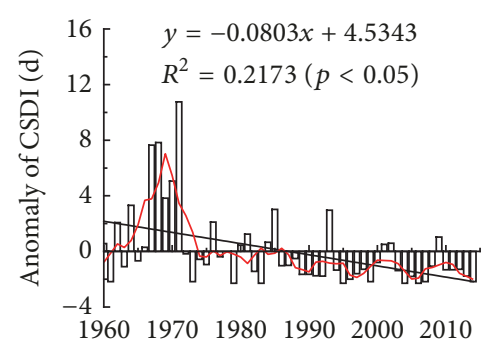

(c)

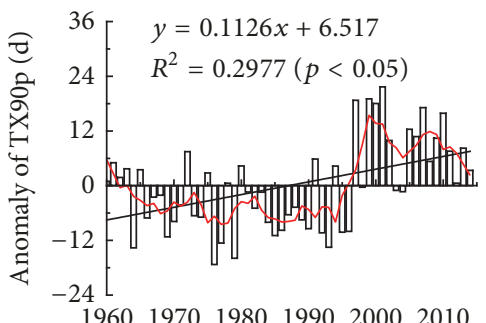

(f)

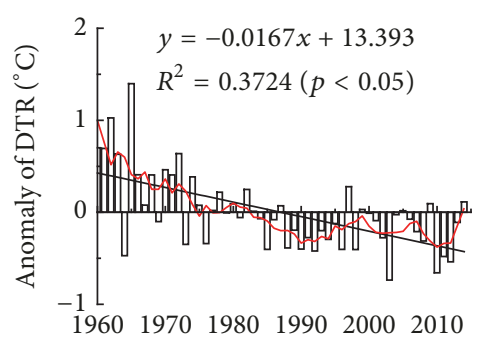

(i)

FIGURE 6: Anomaly of extreme temperature indices curves across the BTSSR (1960-2014). The black line represents the linear trends for (a) TN10p, (b) TX10p, (c) CSDI, (d) TNn, (e) TN90p, (f) TX90p, (g) WSDI, (h) TXx, (i) DTR, and (j) GSL. The redline represents the 5-year moving average.

average slope of $0.75^{\circ} \mathrm{C} /$ decade. A strong increasing trend was observed at the Wutaishan station (SR-III) and a significant negative trend was identified at the Hequ station (SR-I; Figure $9(\mathrm{~d})$ ).

Results for the study period across the BTSSR showed a general trend of warming for the cold-related indices, trends which were also identified in northern Mongolia [96], South Africa [97], northeast China [98], and globally [99]. As extreme low temperature events decreased in the BTSSR, vegetation damage due to freezing conditions was mitigated, thus resulting in an expansion of range northwards of low, cold-tolerant plants which can result in the enrichment of plant species in this area.
4.2.2. Warm-Related Indices. The frequency and duration of extreme high temperature events across the BTSSR are shown by the results for the temporal variation of warm nights (TN90p), warm days (TX90p), and the warm spell duration indicator (WSDI) (Figures 6(e)-6(g)). In general, these indices fluctuated continuously, having a significant increasing trend during the study period $(p<0.01)$. The results for TN90p (with a slope of 1.74 days/decade; Figures $7(\mathrm{e})-7(\mathrm{~g})$, Table 2) were noticeable, these being in accordance with previous findings across China [100]. Results for the different stages showed that the frequency and duration of extreme high temperature recorded an insignificant negative trend during $S_{1}$. Results during $S_{2}$ only recorded significant 


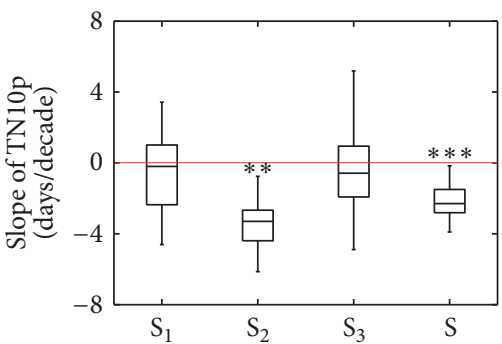

(a)

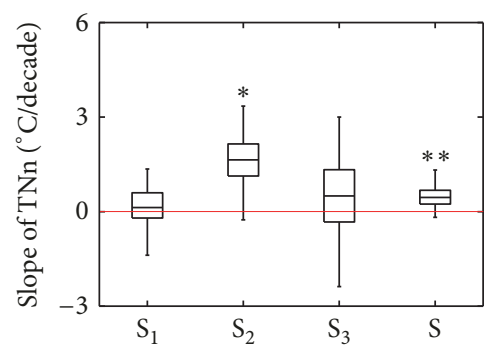

(d)

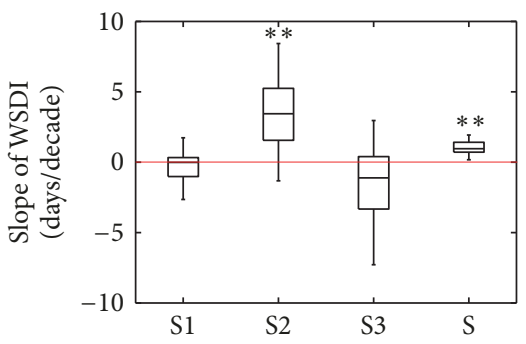

(g)

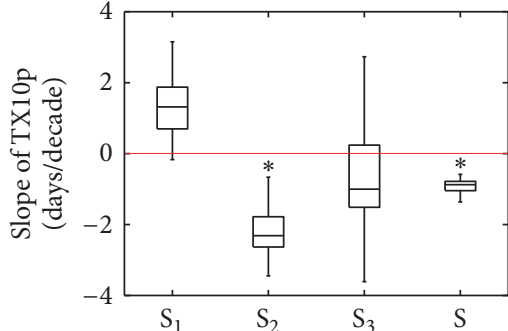

(b)

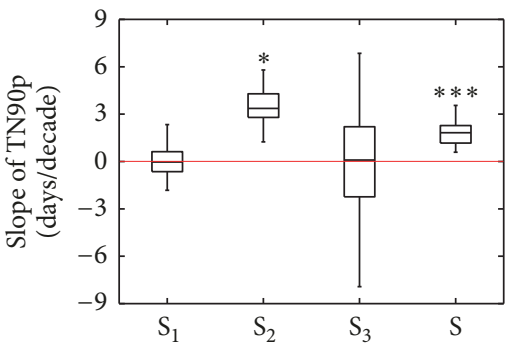

(e)

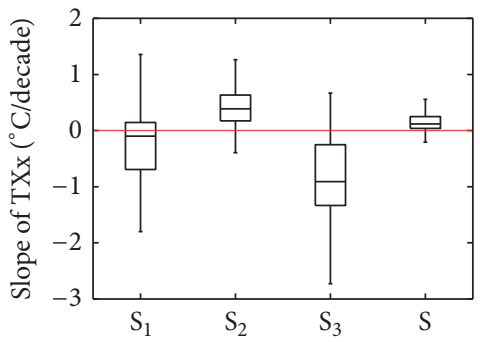

(h)

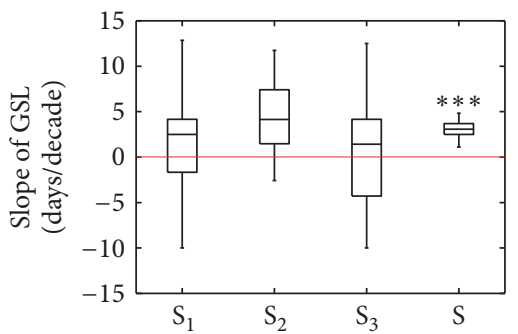

(j)

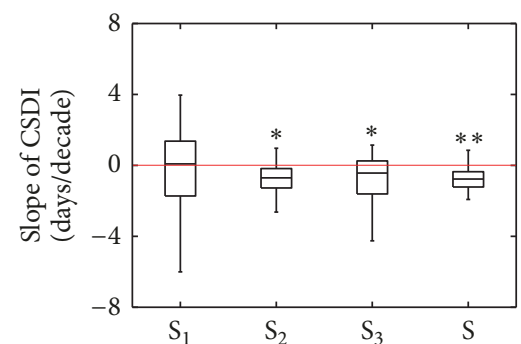

(c)

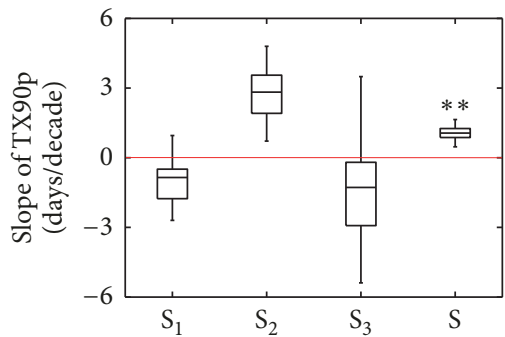

(f)

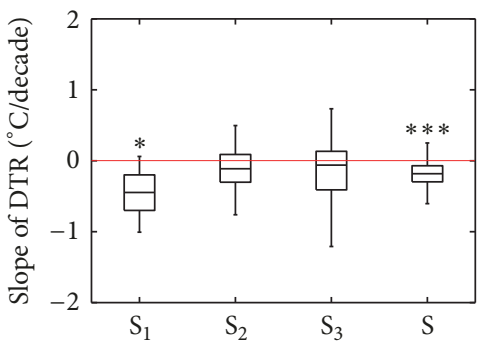

(i)

FIGURE 7: Box-Plot of Slopes for extreme temperature indices across the BTSSR in different stages. (a) TN10p, (b) TX10p, (c) CSDI, (d) TNn, (e) TN90p, (f) TX90p, (g) WSDI, (h) TXx, (i) DTR, and (j) GSL. $\mathrm{S}_{1}$ is 1960-1978, $\mathrm{S}_{2}$ is 1979-2000, $\mathrm{S}_{3}$ is $2000-2014$, and S is 1960-2014. * * * is 0.001 level of significance, $* *$ is 0.01 level of significance, and $*$ is 0.05 level of significance.

increases for TN90p and WSDI; TN90p had the most noticeable increase with a slope of 3.49 days/decade; during $\mathrm{S}_{3}$, the frequency and duration of extreme high temperature decreased (Figures $7(\mathrm{e})-7(\mathrm{~g})$, Table 2$)$. The temporal variation of Max Tmax (TXx) across the BTSSR (Figure 6(h)) from 1960 to 2014 recorded fluctuations to insignificantly increase, having a slope of $0.16^{\circ} \mathrm{C} /$ decade. TXx results during the different stages recorded a slightly negative trend in $S_{1}$, an insignificant increase in $S_{2}$, and an insignificant decrease in $\mathrm{S}_{3}$ (Figure 7(h), Table 2).

Variations in extreme warm indices in the five subregions (Figures $8(\mathrm{e})-8(\mathrm{~h})$, Table 3 ) showed that frequency and duration of extreme high temperature recorded significant increasing trends (1960-2014) for the majority of the subregions, especially TN90p (Figures 10(a)-10(c)). The change of TN90p is more pronounced than that of TX90p, a finding which is in accordance with previous studies [79, 94]. The temporal variation of TXx for the five subregions (Figure 10(d)) shows an increasing trend for all subregions, especially SR-V (with a slope of $0.24^{\circ} \mathrm{C} /$ decade). As daily maximum temperatures increase, transpiration and plant water stress will be exacerbated which may lead to an increase in water demand for vegetation production [101]. All five subregions showed that there was a combination of negative 


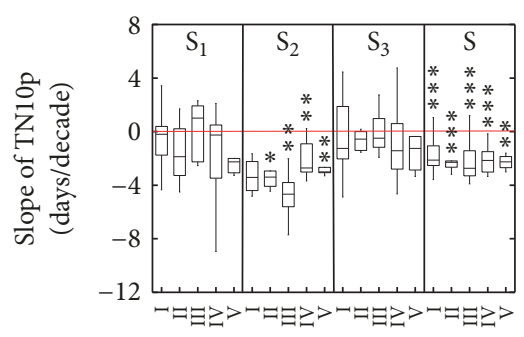

(a)

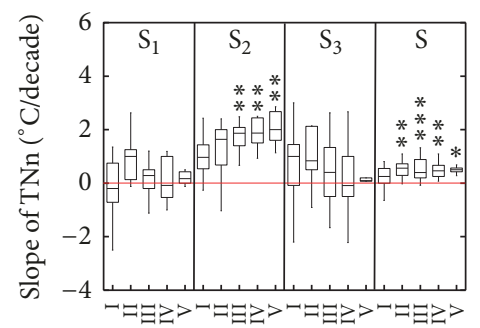

(d)

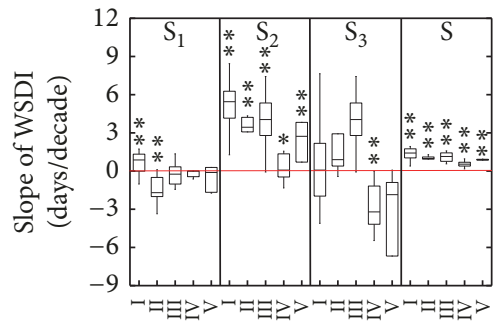

(g)

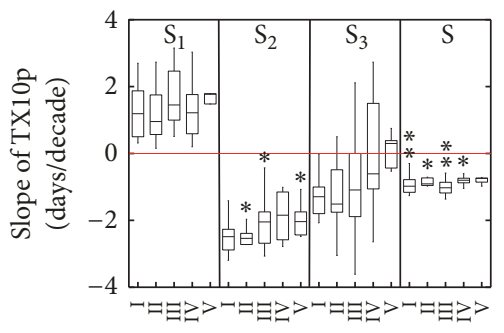

(b)

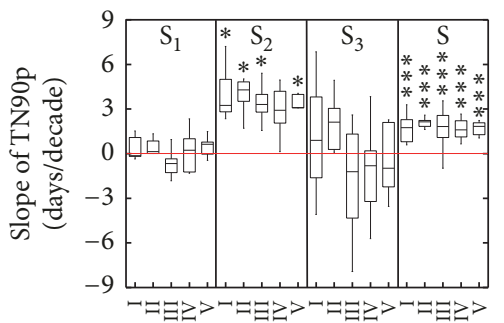

(e)

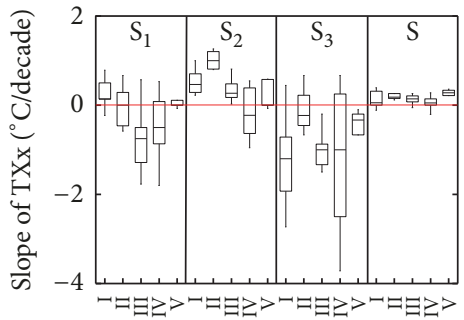

(h)

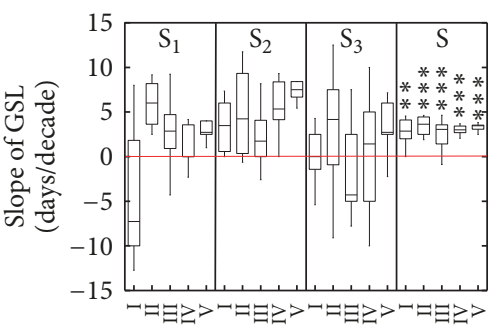

(j)

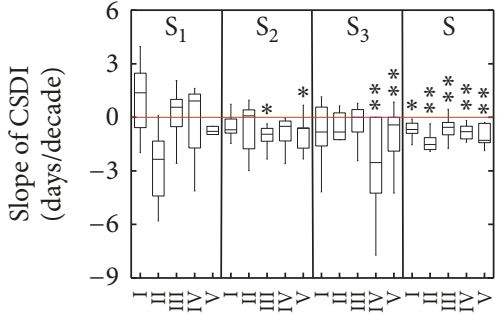

(c)

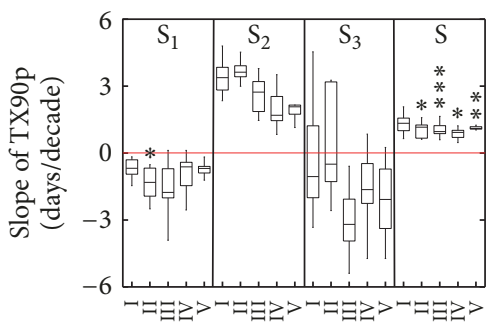

(f)

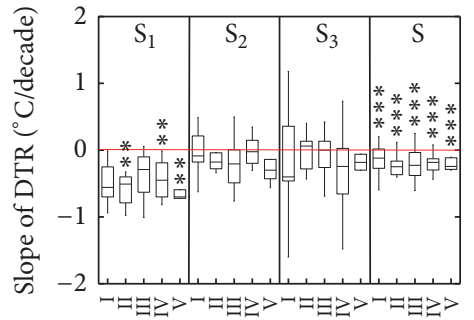

(i)

FIGURE 8: Box-Plot of Slopes for extreme temperature indices across the five subregions in different stages. (a) TN10p, (b) TX10p, (c) CSDI, (d) TNn, (e) TN90p, (f) TX90p, (g) WSDI, (h) TXx, (i) DTR, and (j) GSL. $S_{1}$ is 1960-1978, S is 1979-2000, $\mathrm{S}_{3}$ is 2000-2014, S is 1960-2014. $* * *$ is 0.001 level of significance, $* *$ is 0.01 level of significance, and $*$ is 0.05 level of significance.

and positive trends during $S_{1}$, with more negative trends being identified. During $S_{2}$, an increasing trend occurred for the majority of the subregions, with more insignificant than significant trends, especially for TN90p in SR-III (with a slope of 3.34 days/decade). These findings are also in accordance with changes of temperature extremes in China as a whole [95]. During the last decade $\left(S_{3}\right)$, the five subregions showed a mixture of negative and positive trends, with more negative trends recorded than positive (Figures $8(\mathrm{e})-8(\mathrm{~h})$, Table 3 ).

Results across the BTSSR showed that positive slopes in TN90p occurred across the majority of the region, with the largest trend occurring in the central-southern mountain area. However, negative slopes were identified in the Luanhe River Basin of the southeastern region and the east area of the southwest subregion (SR-I) (Figure 10(a)). Based on data from 47 stations (88.68\% of all stations) (Table 2), the spatial distribution of TN90p showed a significant increase for the BTSSR ( $p<0.05$ ), corresponding to an average slope of 4.58 days/decade. Significant decreasing trends (at the $99 \%$ confidence level) were identified at the Hequ and Chengde stations (Figure 10(a)), accounting for $3.77 \%$ of the total stations, and a strong increasing trend was observed at the Wutaishan station (SR-III).

A positive slope for TX90p was identified across almost the entire BTSSR, the only exception being the southeastern area of SR-I where a negative slope was recorded. The larger positive slopes were recorded in the central-southern mountain area, and the number of stations recording positive 


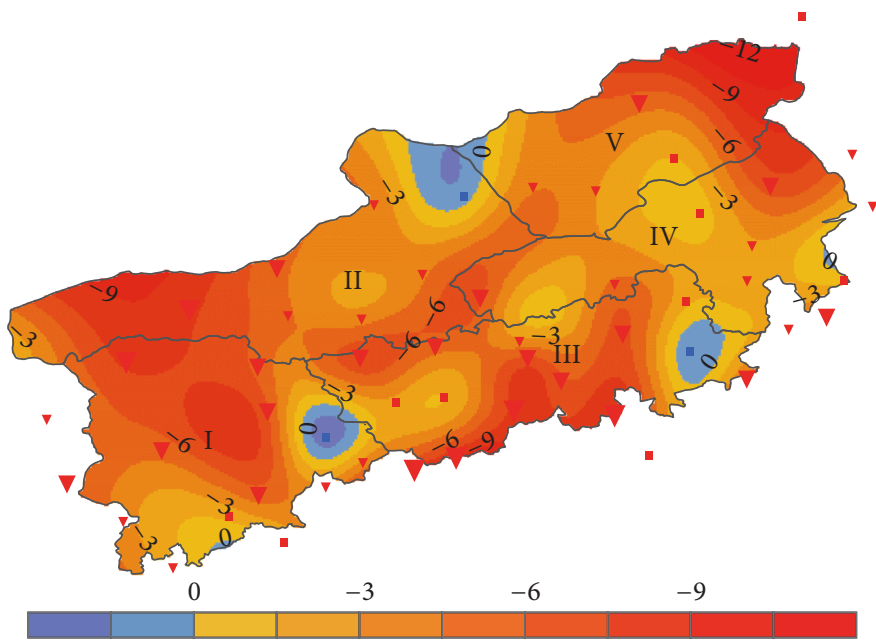

TN10p (days/decade)

$\boldsymbol{\nabla}-9.55--7.73 \quad-2.63-0.00$

$\boldsymbol{\nabla}-7.73--5.00 \quad$ " $0.00-2.31$

$\checkmark-5.00--2.63$
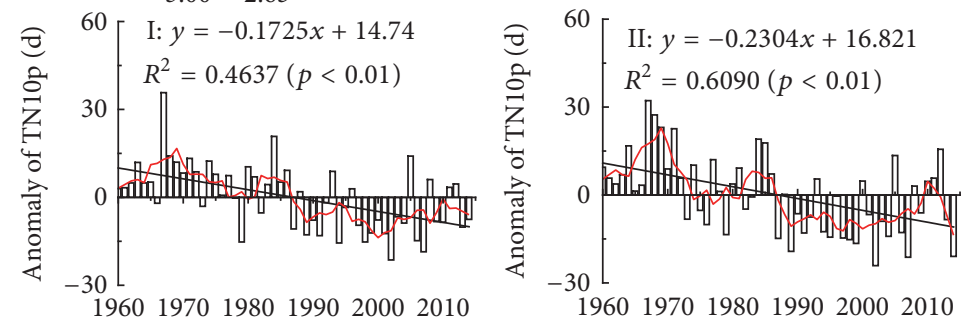

(a)

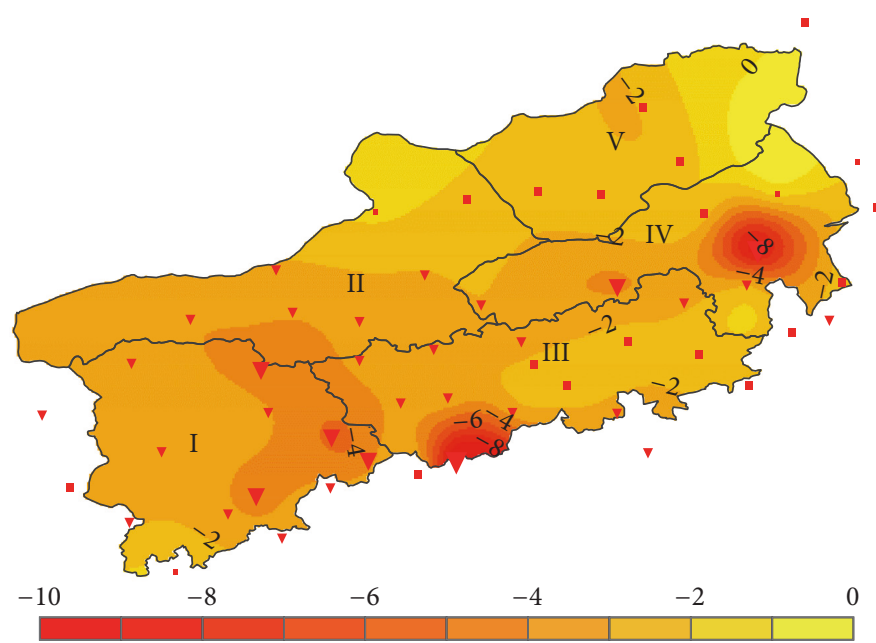

TX10p (days/decade)

$\boldsymbol{\nabla}-10.00--8.33 \quad-2.05--1.11$

$\boldsymbol{\nabla}-8.33--3.08 \quad \cdot-1.11--0.70$

$\checkmark-3.08--2.05$

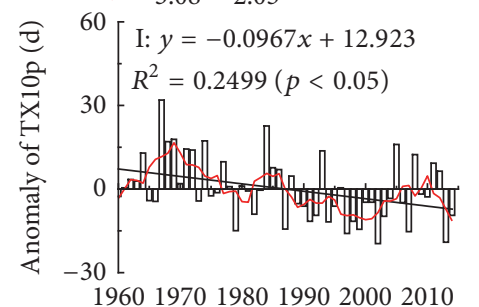

196019701980199020002010

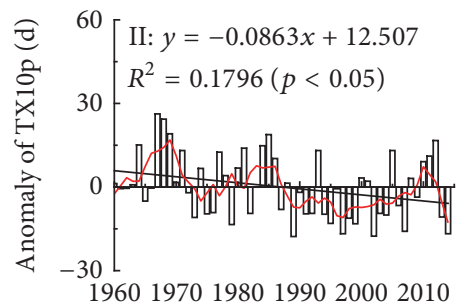

(b)
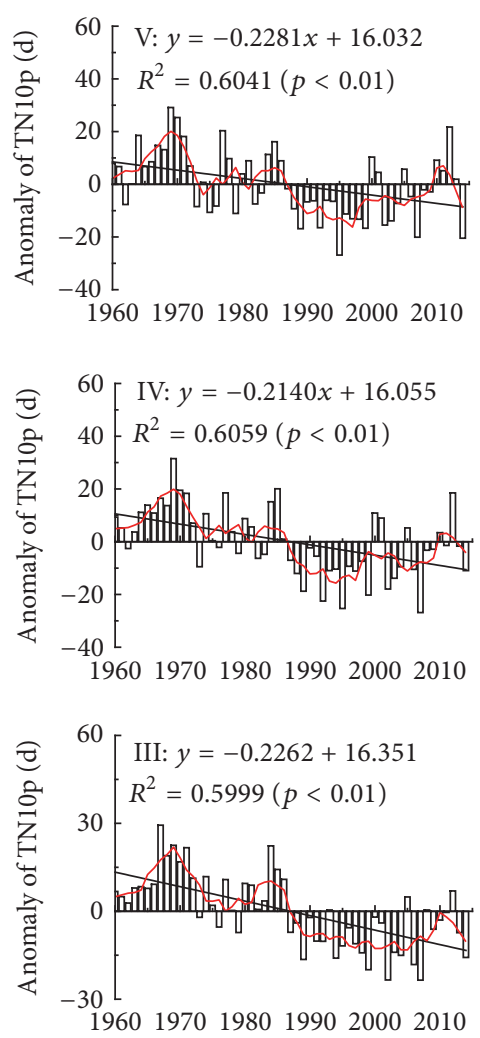
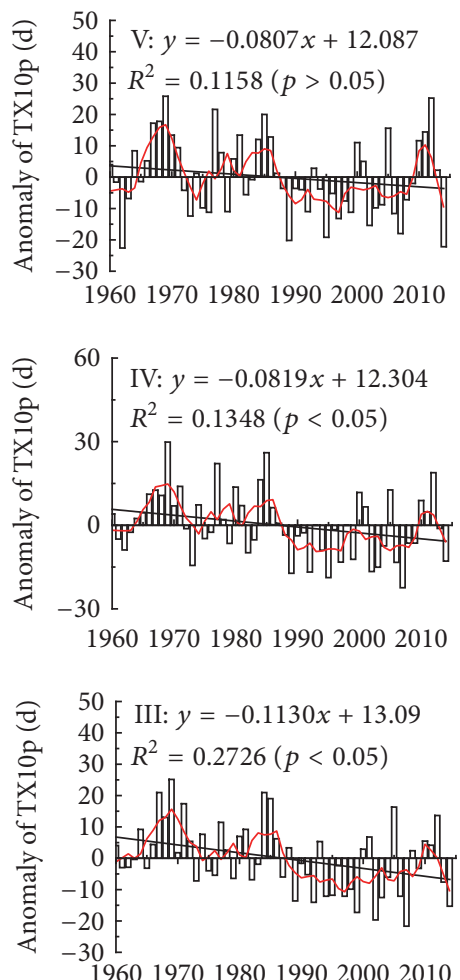

196019701980199020002010

FIGURE 9: Continued. 


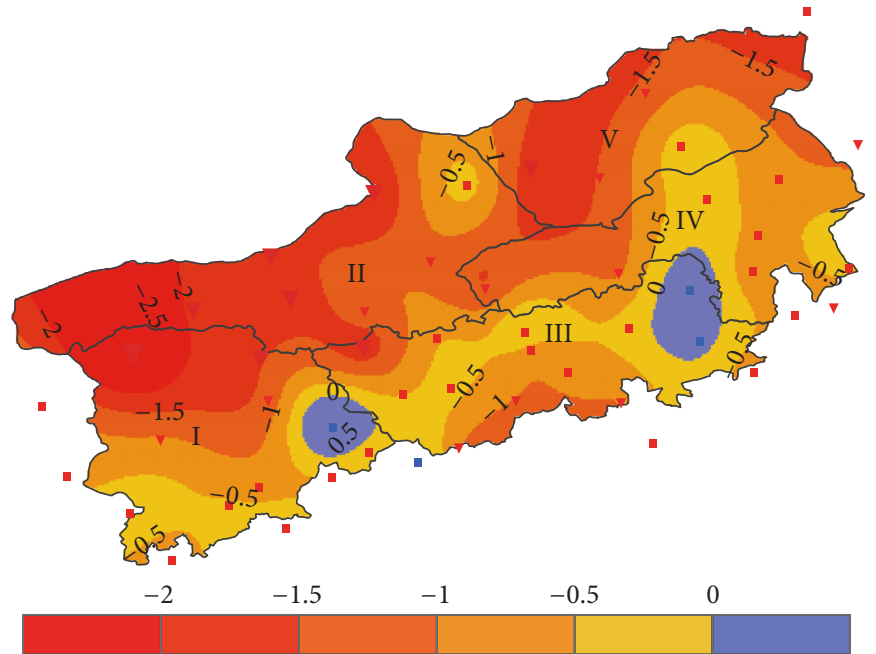

CSDI (days/decade)

$$
\begin{aligned}
& \nabla-2.83--1.92 \quad-\quad-0.90-0.00 \\
& \nabla-1.92--1.52 \quad: 0.00-0.85
\end{aligned}
$$$$
\checkmark-1.52--0.90
$$

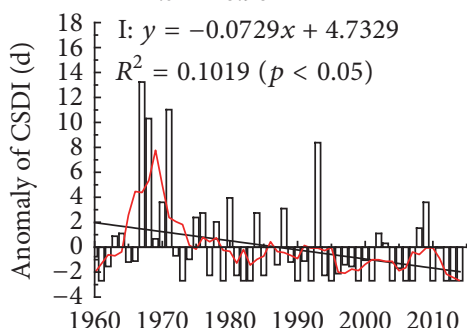

$19601970 \quad 1980199020002010$

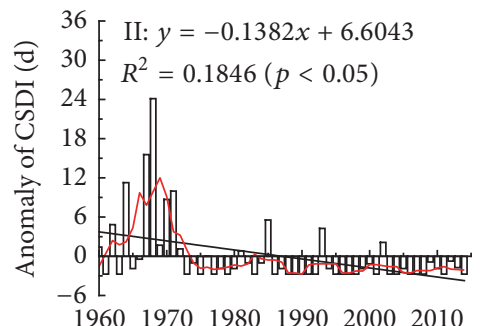

(c)

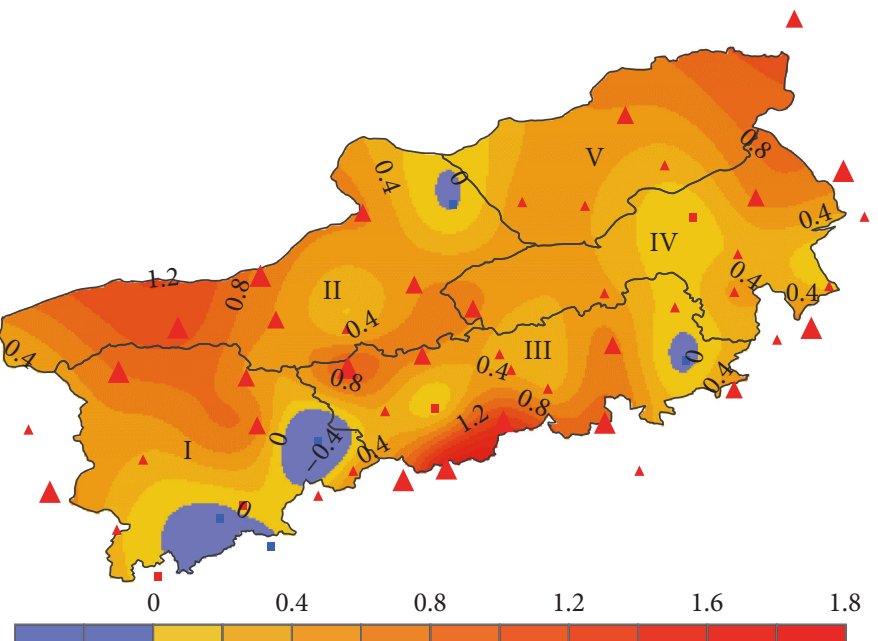

$\mathrm{TNn}\left({ }^{\circ} \mathrm{C} /\right.$ decade $)$

- $-0.65-0.00 \Delta 0.50-0.69$

- $0.00-0.09 \quad \Delta \quad 0.69-1.91$

A $0.09-0.50$

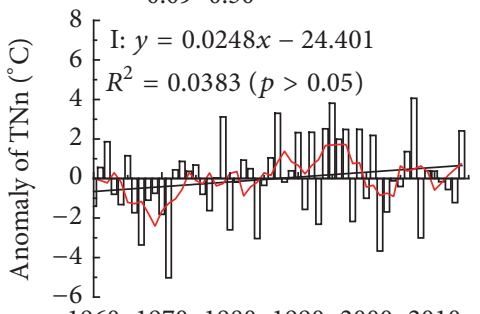

196019701980199020002010

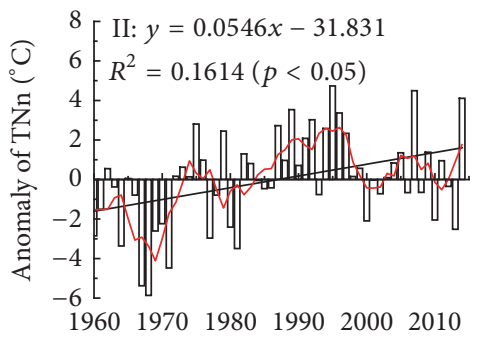

(d)
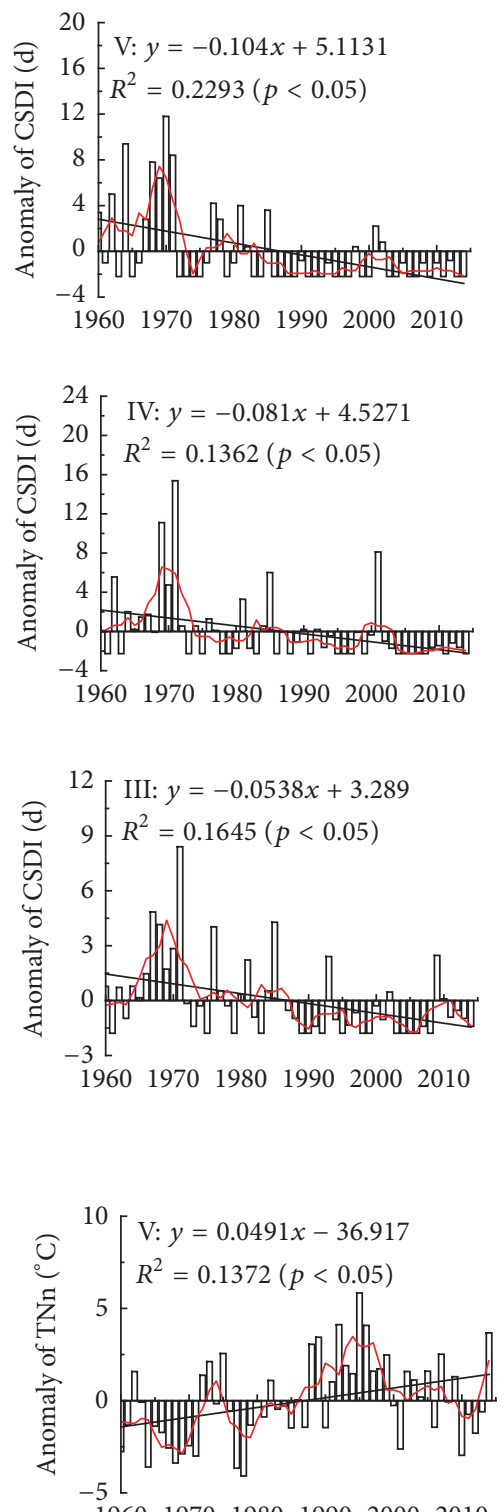

$1960 \quad 1970 \quad 1980 \quad 1990 \quad 2000 \quad 2010$
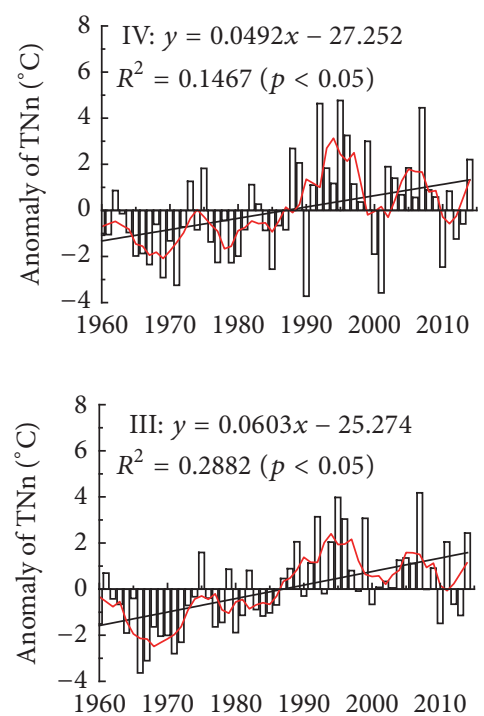

FIGURE 9: Spatial patterns of the trend slopes of cold-related indices across the BTSSR and anomaly of subregional indices curves, 1960-2014.

The black line represents the linear trends for (a) TN10p, (b) TX10p, (c) CSDI, and (d) TNn. The redline represents the 5-year moving average. 


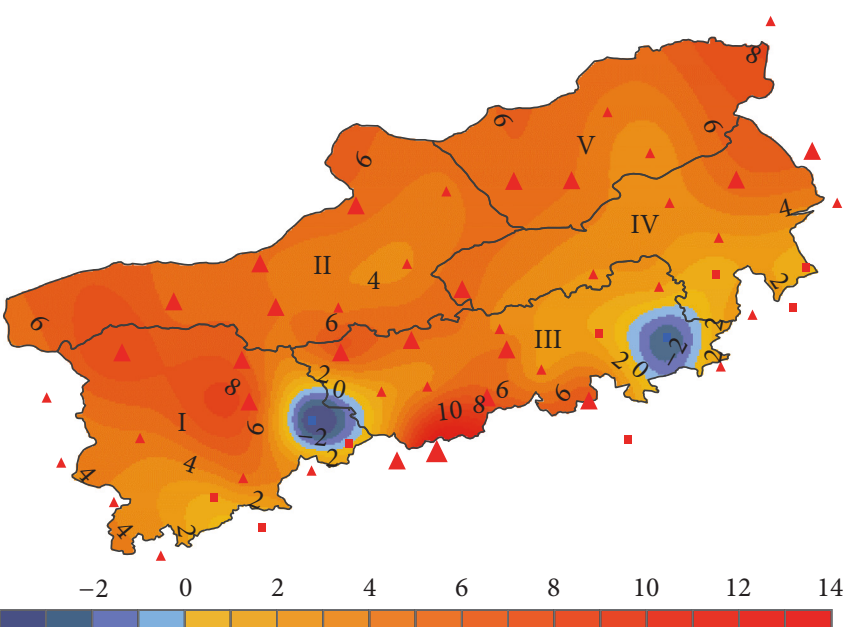

TN90p (days/decade)

- $-4.32-0.00$

A $4.80-7.91$

- $0.00-1.88$

A $7.91-14.23$

$\Delta 1.88-4.80$

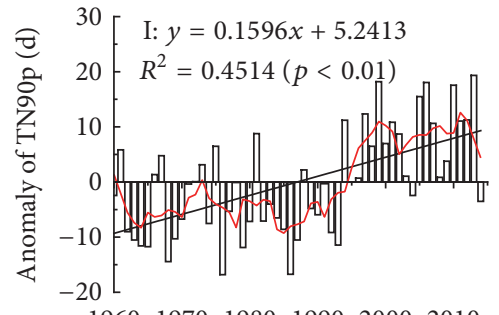

$\begin{array}{llllll}1960 & 1970 & 1980 & 1990 & 2000 & 2010\end{array}$

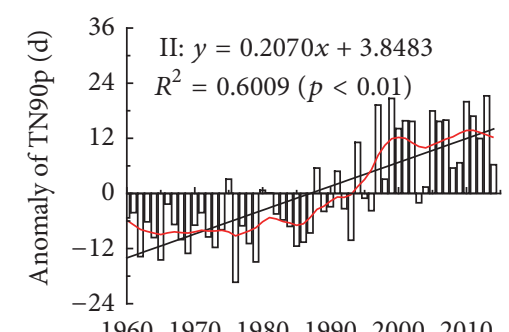

(a)

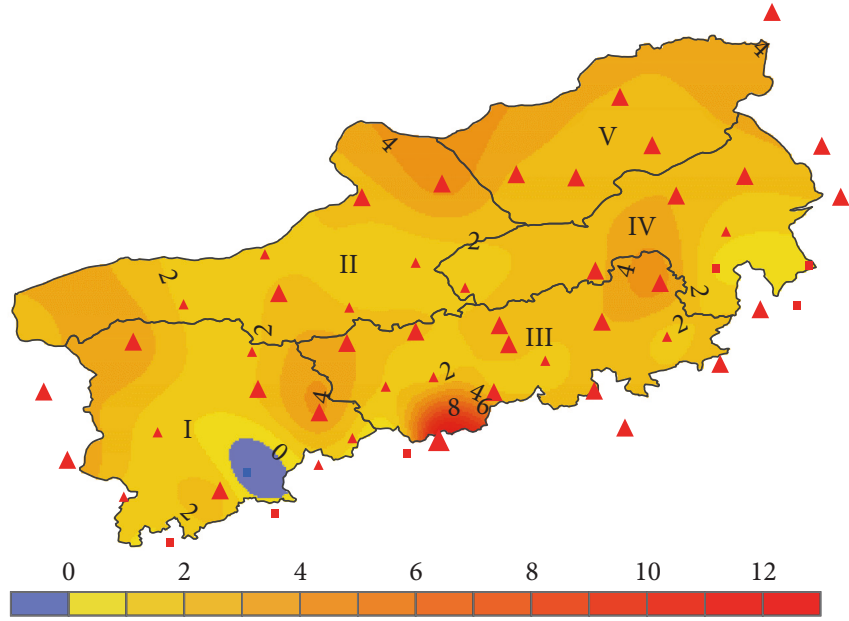

TX90p (days/decade)

- $-1.00-0.00$ \ $2.00-4.44$

- $0.00-0.75$ \ $4.44-13.00$

$\triangle 0.75-2.00$
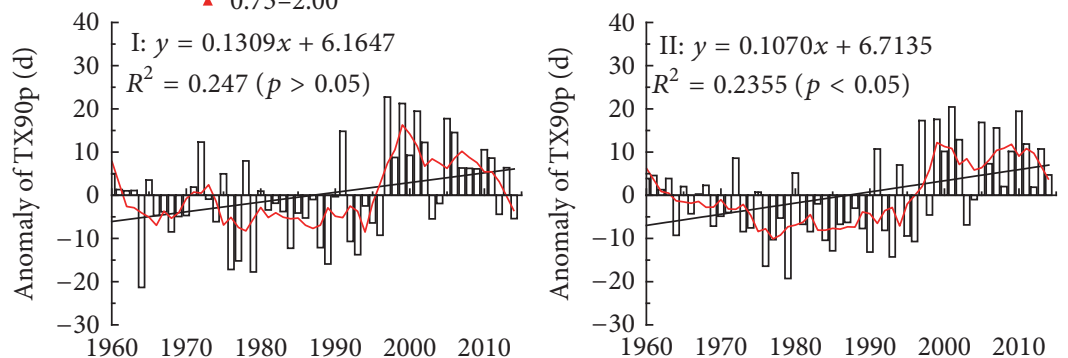

(b)
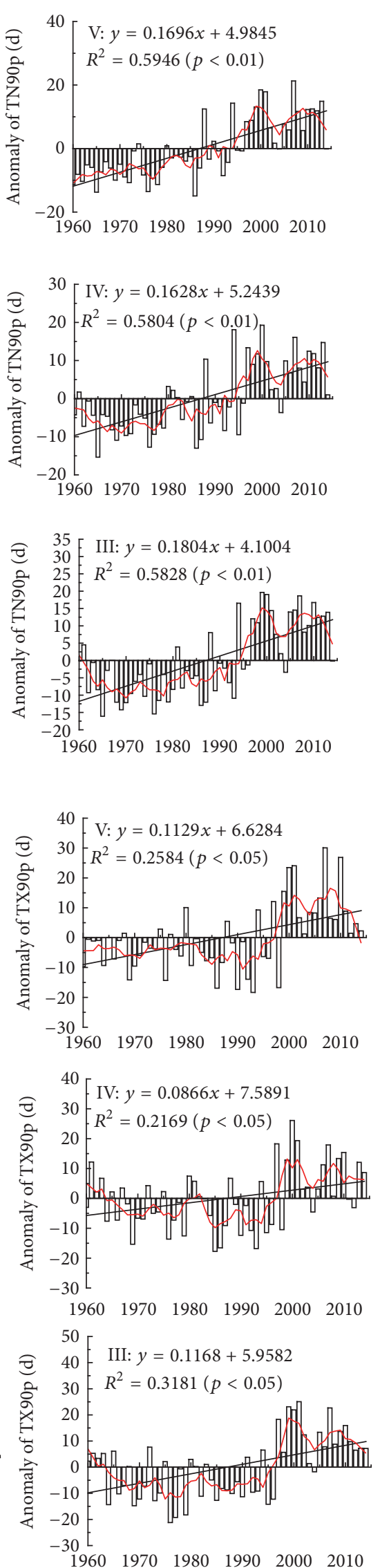

$\begin{array}{llllll}1960 & 1970 & 1980 & 1990 & 2000 & 2010\end{array}$

Figure 10: Continued. 


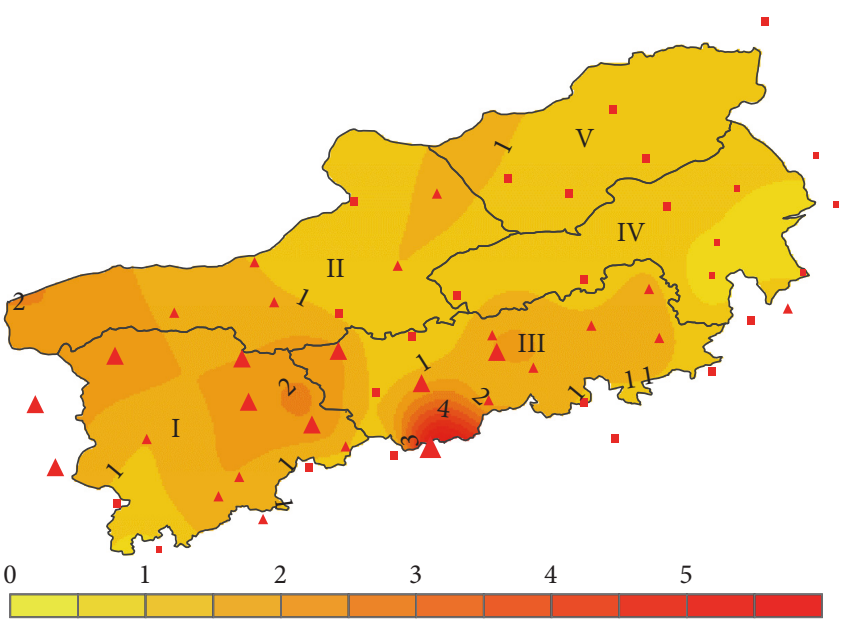

WSDI (days/decade)

- 0.00-0.54

\ 1.46-1.94

- $0.54-0.94$

А $1.94-5.45$

4. $0.94-1.46$
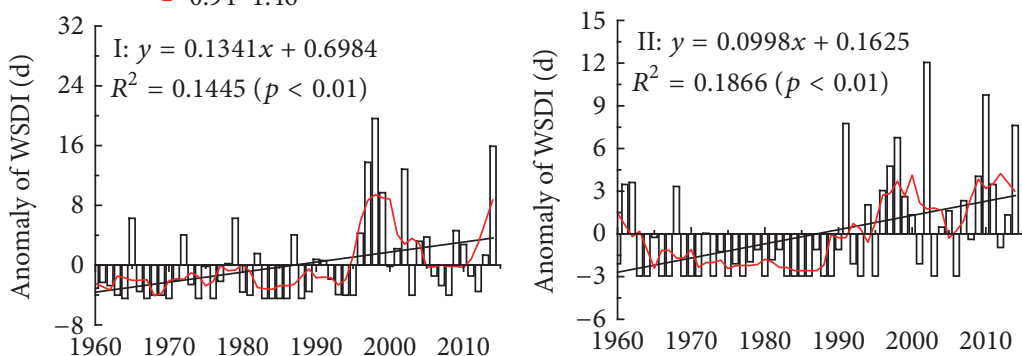

(c)

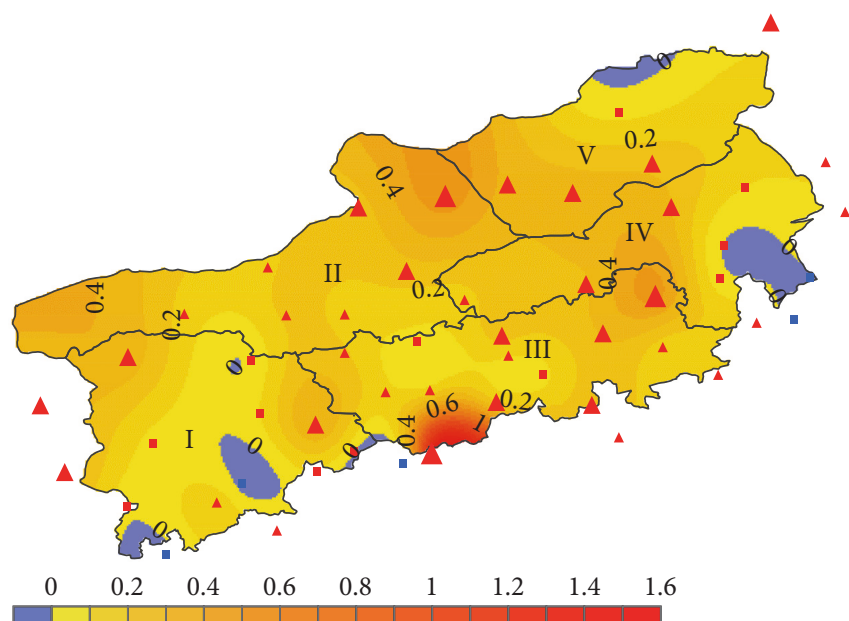

TXx $\left({ }^{\circ} \mathrm{C} /\right.$ decade $)$

- $-0.09-0.00$

- $0.21-0.38$

- $0.00-0.09$

- $0.38-1.61$

4 $0.09-0.21$

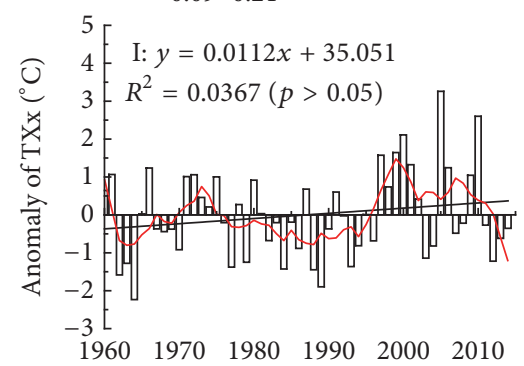

$1960 \quad 1970 \quad 1980 \quad 1990 \quad 2000 \quad 2010$

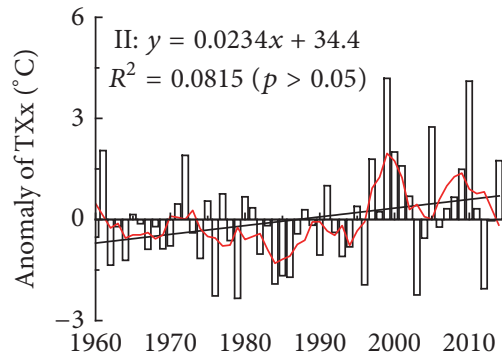

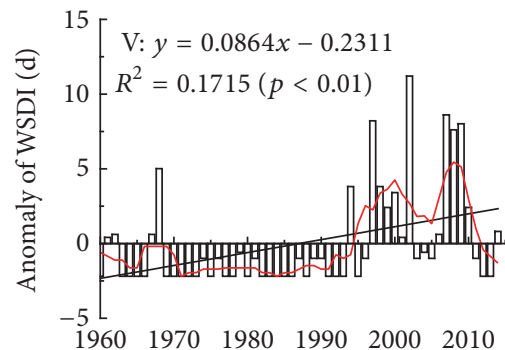
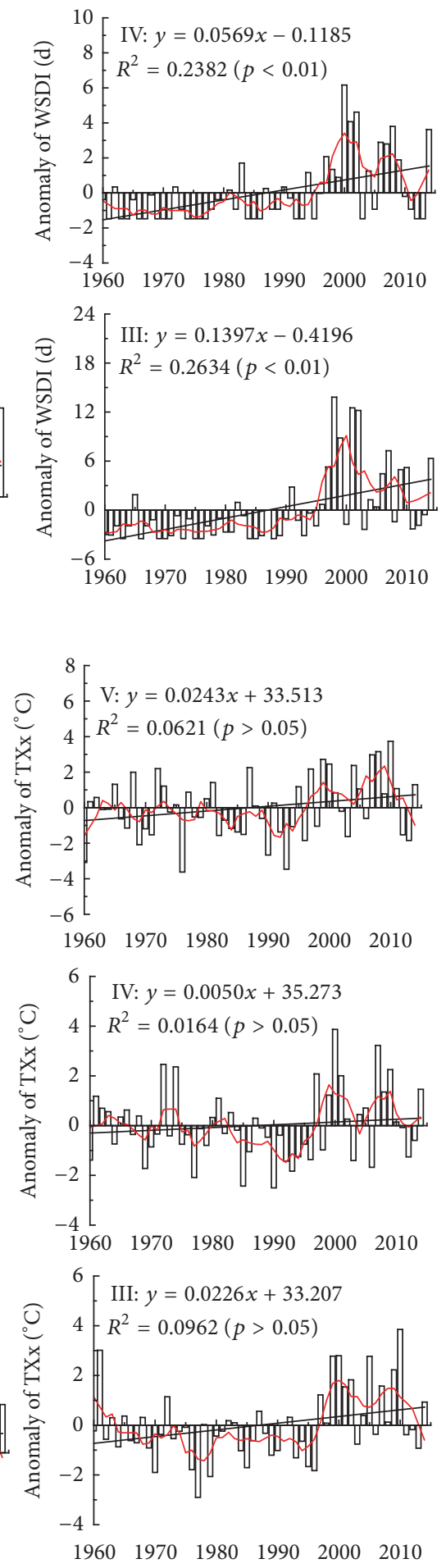

(d)

FIGURE 10: Spatial patterns of the trend slopes of warm-related indices across the BTSSR and anomaly of subregional indices curves, $1960-2014$. The black line represents the linear trends for (a) TN90p, (b) TX90p, (c) WSDI, and (d) TXx. The redline represents the 5-year moving average. 
trends was much larger than those recording negative trends (Figure 10(b)). Twenty-nine stations recorded significant increases (54.72\% of the total stations), with the Wutaishan station in SR-III recording the strongest increasing trend, and only one station recorded a decrease (Table 2; Figure 10(b)).

WSDI results across the region recorded positive slopes, with the largest being in the central-southern mountain area (Figure 10(c)). Positive trends were significant at 42 stations (79.25\%), these being evenly distributed across the region; there were no negative trends recorded for this variable (Figure 10(c), Table 2). The strongest increasing trend was observed at the Wutaishan station in SR-III (Figure 10(c)).

TXx slope distribution results across the BTSSR showed a spatial disparity. Negative slopes were identified in the eastern and southern areas of SR-I, in southeastern areas of SR$\mathrm{IV}$, and in the northern area of SR-V. Positive slopes were present in the other areas of the study region, with the highest positive slopes occurring in the central-southern mountain area (Figure 10(d)). The number of stations recording positive trends was much greater than those recording negative trends; 10 stations recorded significant increases (18.87\%), with no significant decreases being recorded at any station (Table 2). The strongest increasing trend was recorded at the Wutaishan station (SR-III; Figure 10(d)).

Differences in results between the minimum nighttime temperature (TNn) and the maximum daytime temperature (TXx) (Figures 7(d) and 7(h), Table 2) indicated that temperatures across the BTSSR showed a general warming trend, a result which is consistent with global increases [102]. The rate of warming of TXx was lower than that of TNn over all of the subregions (Figures $8(\mathrm{~d})$ and $8(\mathrm{~h})$, Table 3 ), an occurrence which is not conducive to daytime vegetation growth; this warming will have the opposite effect on nighttime vegetation growth by affecting carbon absorption and consumption [103, 104]. Moreover, the increase of maximum daily temperature may inhibit the growth of grass across the BTSSR; an increase of the minimum temperature may promote grassland growth via the compensatory effect of increasing nocturnal respiration [105], as well as reducing desert vegetation productivity by accelerating plant respiration [106], increasing the rate of nutrient metabolism, and shortening the duration of grain filling $[107,108]$.

4.2.3. Variability Indices. The temporal variation of the diurnal temperature range (DTR) across the BTSSR showed DTR fluctuations to continuously significantly decrease $(p<$ 0.001 ), with a slope of $-0.17^{\circ} \mathrm{C} /$ decade (Figures 6(i) and 7(i), Table 2). During the different stages, DTR showed a significant negative trend during $S_{1}$ (with a slope of $-0.43^{\circ} \mathrm{C} /$ decade; $p<0.05$ ), and insignificant decreases during $\mathrm{S}_{2}$ and $\mathrm{S}_{3}$ (Figure 7(i), Table 2). DTR trend variations for the different stages for the majority of the five subregions (Figure 8(i), Table 3) showed a significant decreasing trend across the study period, especially in SR-II which had a slope of $-0.23^{\circ} \mathrm{C} /$ decade (Figures $8(\mathrm{i})$ and $11(\mathrm{a})$, Table 3$)$. All five subregions showed negative trends during $\mathrm{S}_{1}$; SR-II recorded a more significant trend, having a slope of $-0.60^{\circ} \mathrm{C} /$ decade. During $\mathrm{S}_{2}$, insignificant decreasing trends were recorded for all subregions, and during the last decade $\left(\mathrm{S}_{3}\right)$ the five subregions showed negative trends (Figure 8(i), Table 3). Higher DTR is propitious to the accumulation of biomass $[93,109]$, therefore, in the BTSSR, as DTR decreased the quality of vegetation may decline.

The slope distribution of DTR shows a spatial disparity in the BTSSR (Figure 11(a)). A positive slope was recorded in the north, east, and southwestern areas of the region, and a negative slope prevailed in the other areas where higher negative slopes occurred along the northeast-northwest border and the central-southern mountain area. Based on data from 35 stations (66.04\% of all stations), the spatial distribution of DTR showed a significant decrease across the BTSSR $(p<0.05)$ (Table 2), corresponding to an average slope of $-0.29^{\circ} \mathrm{C} /$ decade. Seven stations (13.21\% of total stations) had a significant increasing trend at the $95 \%$ confidence level. A strong decreasing trend was observed at the Weixian station (SR-III) and a strong increasing trend was observed at the Hequ station (SR-I; Figure 11(a)).

The temporal variation of the growing season length (GSL) across the BTSSR during the study period continuously increased significantly by 3.20 days/decade from 1960 to 2014 $(p<0.001)$ (Figures 6(j) and 7(j), Table 2). Results for the three stages showed that GSL across the BTSSR showed an insignificant positive trend during $S_{1}, S_{2}$, and $S_{3}$ (Figure $7(j$ ), Table 2). The variations in GSL trends for the different stages in the five subregions showed significant increasing trends for the majority of the subregions during the study period, especially for GSL results in SR-II (with a slope of 3.42 days/decade; Table 3, Figures $8(\mathrm{j})$ and $11(\mathrm{~b})$ ). As the length of the growing season increased, the potential number of harvests and seasonal yields for perennial forage crops may be promoted at high latitudes [110]. All five subregions showed a mixture of negative and positive trends, with more positive trends recorded during $\mathrm{S}_{1}$. During $\mathrm{S}_{2}$, insignificant increasing trends occurred for all subregions and, during the last decade $\left(\mathrm{S}_{3}\right)$, the five subregions recorded a mixture of negative and positive trends, with more positive than negative trends recorded (Figure $8(\mathrm{j})$, Table 3 ).

The slope distribution of GSL shows a spatial disparity across the BTSSR (Figure 11(b)). Negative slopes were recorded in the eastern areas of SR-III and positive slopes were recorded for all of the other areas in the region; the highest positive slopes occurred in the central-southern mountain area. The number of stations recording positive trends was much greater than those recording negative trends; 42 stations recorded significant increases (79.25\%) and no station recorded a significant decrease (Table 2). A strong increasing trend was observed at the Wutaishan station (SR-III) and a negative trend was only found at the Chengde station (SR-III; Figure 11(b)).

\section{Conclusions}

Based on daily temperature data from 53 meteorological stations across the Beijing-Tianjin Sand Source Region (BTSSR), spanning 1960-2014, annual and seasonal temperature temporal and spatial trends were analyzed, as well as extreme temperature, using the Mann-Kendall test, Sen's slope estimator, and linear regression. 

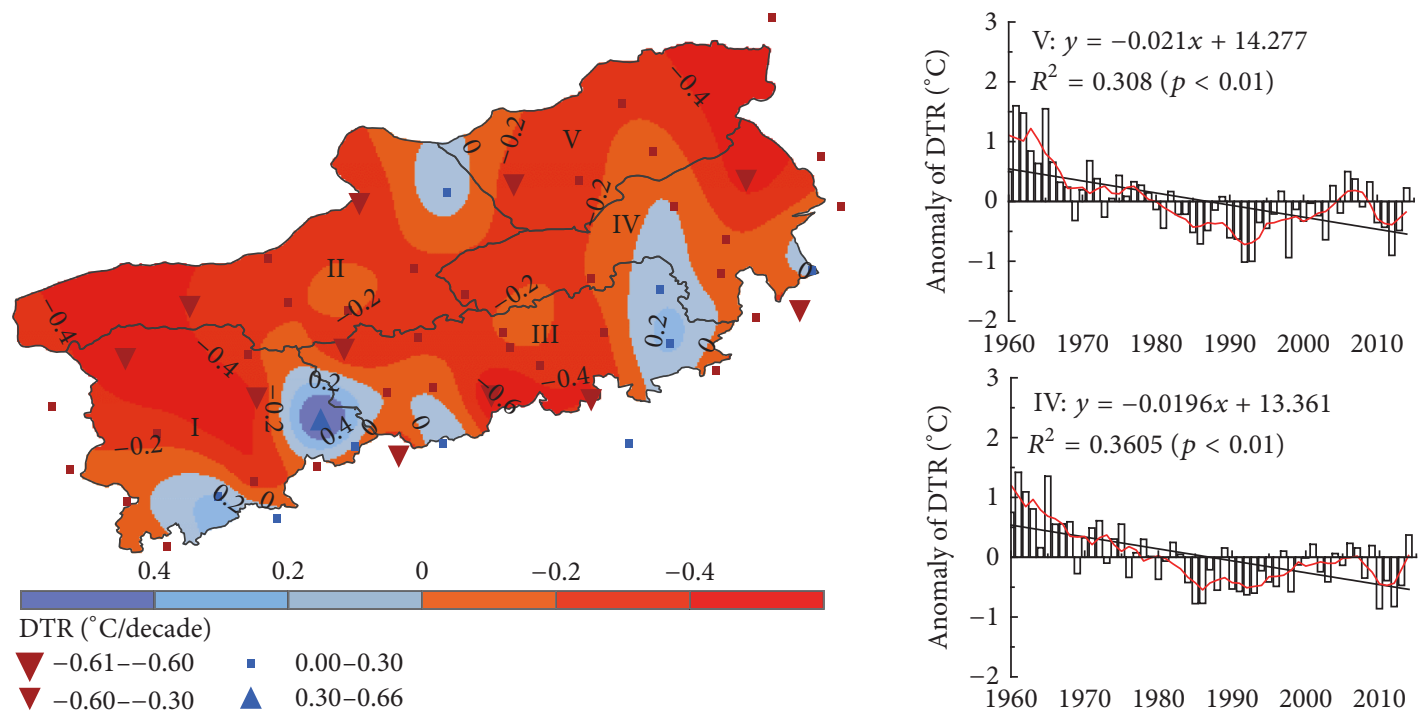

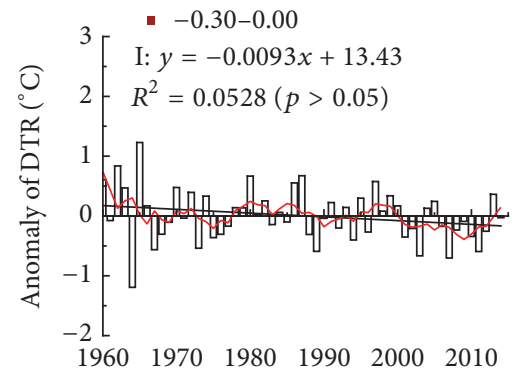

$1960 \quad 1970 \quad 1980 \quad 1990 \quad 2000 \quad 2010$

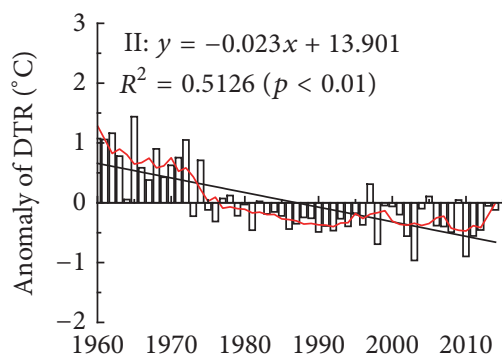

(a)

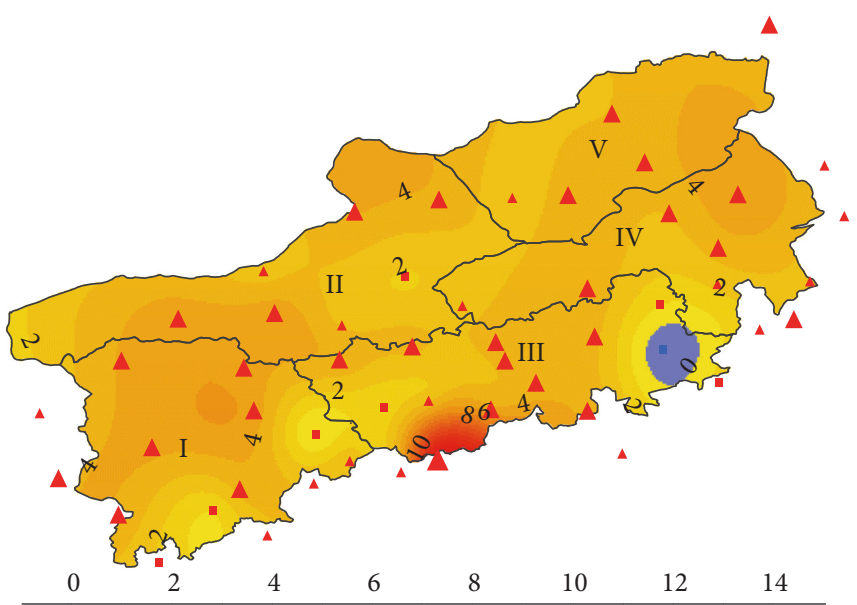

GSL (days/decade)

- $-0.88-0.00$ a 3.00-10.00

- $0.00-1.95$ \ 10.00-15.14

$1.95-3.00$

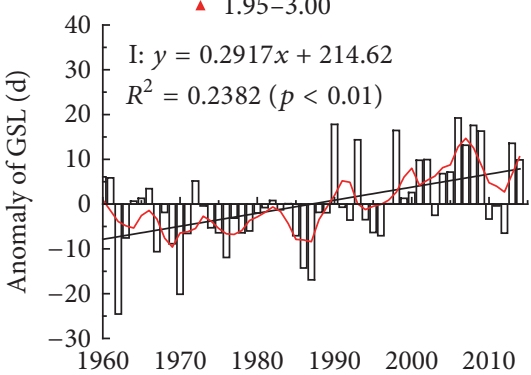

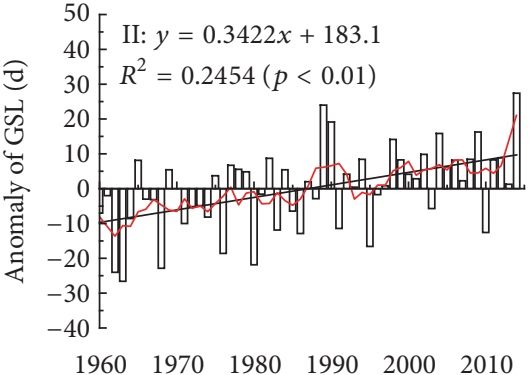

$\begin{array}{llllll}1960 & 1970 & 1980 & 1990 & 2000 & 2010\end{array}$
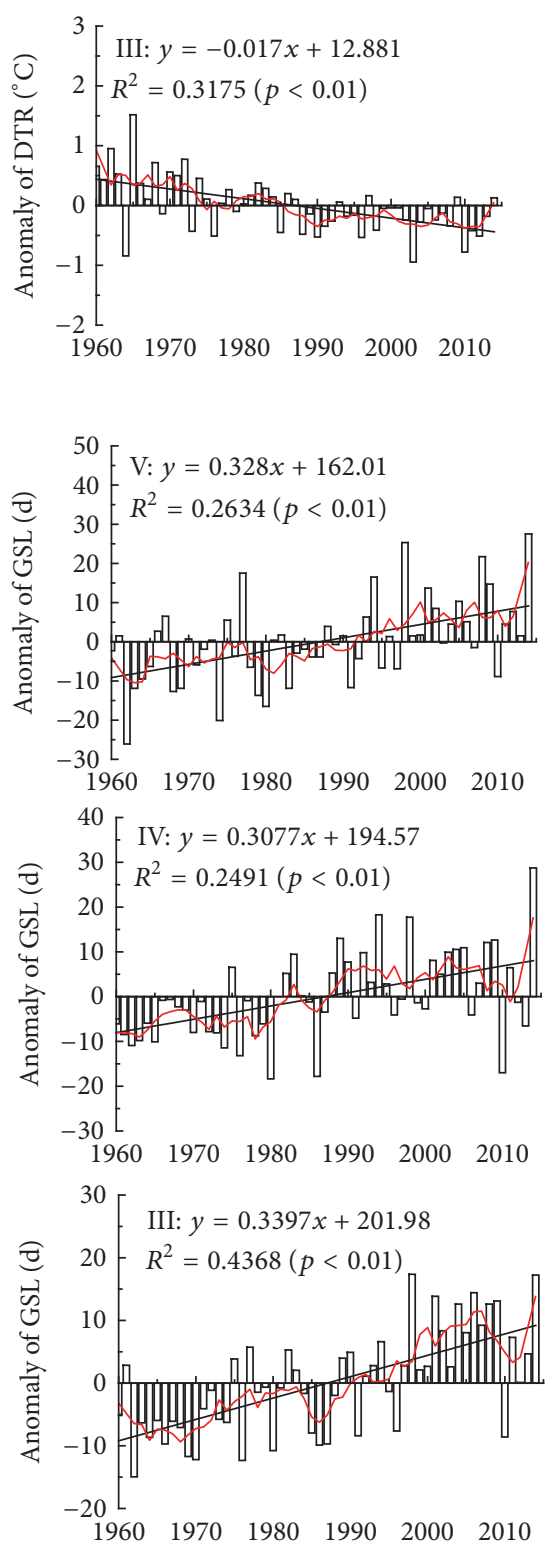

(b)

FIGURE 11: Spatial patterns of the trend slopes of variability indices over the BTSSR and anomaly of subregional indices curves, $1960-2014$.

The black line represents the linear trends for (a) DTR, (b) GSL. The redline represents 5-year moving average. 
Results from 1960 to 2014 showed that a long-term warming trend is evident in this region which is affecting weather conditions. Across the whole area, annual temperature recorded a significant increase of $0.34^{\circ} \mathrm{C} /$ decade, with the trend test for annual temperature showing that the majority of meteorological stations (96.23\% of all stations) exhibited an increasing trend at the $95 \%$ confidence level. The highest upward trends were recorded during the winter for the five subregions, with winter temperature in SR-III exhibiting the most significant increasing trend (with a value of $0.50^{\circ} \mathrm{C} /$ decade).

Significant upward trends were also recorded in warmrelated extreme temperature indices (TN90p, TX90p, and WSDI), a cold extreme index (TNn) and growing season length (GSL) during the study period, while significant downward trends were identified in cold-related extreme temperature indices (TN10p, TX10p, and CSDI) and for the diurnal temperature range (DTR). In addition, cold nights (TN10p) in SR-III and warm nights (TN90p) in SRII exhibited higher warming trends with values of -2.30 and 2.07 days/decade, respectively. A higher positive slope for extreme temperature indices was recorded in the west, southcentral, and northeastern regions; higher negative slopes occurred in the northwest, south-central, and eastern regions. A higher warming slope was also recorded in extreme temperature along the northeast border, northwest border, and in the central-south mountain part. The trend test in extreme temperature showed that most stations $(>79.25 \%$ of all stations) exhibited a warming trend.

A warming trend for temperature and extremes can result in accelerated plant growth, alleviate plant damage due to freezing, and increase the possibility of using low coldtolerant plants to revegetate in the BTSSR. As the length of the growing season increases, the potential number of harvests and seasonal yields for perennial forage crops may also be promoted at high latitudes. However, in water-limited areas of the BTSSR, increasing temperatures during the growing season may exacerbate rain-fed plant stress due to higher temperatures and a decrease in precipitation, especially vegetation (shrubs or trees) used for restoration of degraded areas. The increase of the minimum temperature may also reduce productivity of desert vegetation by accelerating plant respiration across the BTSSR.

The accurate estimation of changes of temperature and extremes across the BTSSR may be useful for designing and operating appropriate irrigation systems, as well as revegetation strategies, to protect vulnerable arid and semiarid ecosystems against degradation. These findings may be very important for the implementation of future phases of the regeneration project in this area.

\section{Conflicts of Interest}

The authors declare that they have no conflicts of interest.

\section{Acknowledgments}

This research was supported by the International Science \& Technology Cooperation Program of China
(2015DFR31130), the National Key Research and Development Program of China (2016YFC0500801; 2016YFC0500804; 2016YFC0500908), the Fundamental Research Funds of CAF (CAFYBB2017ZA006), and the National Natural Science Foundation of China (31670715; 41471029; 41271033; 41371500; 31200350; 41701249).

\section{References}

[1] IPCC, Climate Change 2013-The Physical Science Basis. Contribution of Working Group I to the Fifth Assessment Report of the Intergovernmental Panel on Climate Change, Cambridge University Press, Cambridge, UK, 2013.

[2] S. J. Asl, A. M. Khorshiddoust, Y. Dinpashoh, and F. Sarafrouzeh, "Frequency analysis of climate extreme events in Zanjan, Iran," Stochastic Environmental Research and Risk Assessment, vol. 27, no. 7, pp. 1637-1650, 2013.

[3] J. Caesar, L. Alexander, and R. Vose, "Large-scale changes in observe daily maximum and minimum temperatures: creation and analysis of a new gridded data set," Journal of Geophysical Research: Atmospheres, vol. 111, no. 5, Article ID D05101, 2006.

[4] J. A. Marengo, M. Rusticucci, O. Penalba, and M. Renom, "An intercomparison of observed and simulated extreme rainfall and temperature events during the last half of the twentieth century: Part 2: Historical trends," Climatic Change, vol. 98, no. 3, pp. 509-529, 2010.

[5] M. R. Haylock, T. C. Peterson, L. M. Alves et al., "Trends in total and extreme South American rainfall in 1960-2000 and links with sea surface temperature," Journal of Climate, vol. 19, no. 8, pp. 1490-1512, 2006.

[6] M. Rusticucci and B. Tencer, "Observed changes in return values of annual temperature extremes over Argentina," Journal of Climate, vol. 21, no. 21, pp. 5455-5467, 2008.

[7] L. A. Vincent, T. C. Peterson, V. R. Barros et al., "Observed trends in indices of daily temperature extremes in South America, 1960-2002," Journal of Climate, vol. 18, no. 23, pp. 5011-5023, 2005.

[8] S. Rehman and L. M. Al-Hadhrami, "Extreme temperature trends on the West Coast of Saudi Arabia," Atmospheric and Climate Sciences, vol. 2, no. 3, pp. 351-361, 2012.

[9] K. Khomsi, G. Mahe, Y. Tramblay, M. Sinan, and M. Snoussi, "Regional impacts of global change: Seasonal trends in extreme rainfall, run-off and temperature in two contrasting regions of Morocco," Natural Hazards and Earth System Sciences, vol. 16, no. 5, pp. 1079-1090, 2016.

[10] M. Piccarreta, M. Lazzari, and A. Pasini, "Trends in daily temperature extremes over the Basilicata region (southern Italy) from 1951 to 2010 in a Mediterranean climatic context," International Journal of Climatology, vol. 35, no. 8, pp. 19641975, 2015.

[11] S. N. Marigi, A. K. Njogu, and W. N. Githungo, "Trends of extreme temperature and rainfall indices for arid and semiarid lands of South Eastern Kenya," Journal of Geoscience and Environment Protection, vol. 04, no. 12, pp. 158-171, 2016.

[12] A. Grundstein and J. Dowd, "Trends in extreme apparent temperatures over the United States, 1949-2010," Journal of Applied Meteorology and Climatology, vol. 50, no. 8, pp. 16501653, 2011.

[13] J. Tian, J. Liu, J. Wang, C. Li, H. Nie, and F. Yu, "Trend analysis of temperature and precipitation extremes in major grain producing area of China," International Journal of Climatology, vol. 37, no. 2, pp. 672-687, 2017. 
[14] K. Zhong, F. Zheng, H. Wu, C. Qin, and X. Xu, "Dynamic changes in temperature extremes and their association with atmospheric circulation patterns in the Songhua River Basin, China," Atmospheric Research, vol. 190, pp. 77-88, 2017.

[15] W. Sun, X. Mu, X. Song, D. Wu, A. Cheng, and B. Qiu, "Changes in extreme temperature and precipitation events in the Loess Plateau (China) during 1960-2013 under global warming," Atmospheric Research, vol. 168, pp. 33-48, 2016.

[16] N. Brooks, M. Legrand, S. J. McLaren et al., Linking Climate Change to Land Surface Change, Springer, Netherlands, 2000.

[17] S. Fall, D. Niyogi, A. Gluhovsky, R. A. Pielke, E. Kalnay, and G. Rochon, "Impacts of land use land cover on temperature trends over the continental United States: assessment using the North American Regional Reanalysis," International Journal of Climatology, vol. 30, no. 13, pp. 1980-1993, 2010.

[18] T. Jie and L. Nianfeng, "Some problems of ecological environmental geology in arid and semiarid areas of China," Environmental Geology, vol. 26, no. 1, pp. 64-67, 1995.

[19] J. G. Han, Y. J. Zhang, C. J. Wang et al., "Rangeland degradation and restoration management in China," The Rangeland Journal, vol. 30, no. 2, pp. 233-239, 2008.

[20] J. Liu and J. Diamond, "China's environment in a globalizing world," Nature, vol. 435, no. 7046, pp. 1179-1186, 2005.

[21] J. Wu, L. Zhao, Y. Zheng, and A. Lü, "Regional differences in the relationship between climatic factors, vegetation, land surface conditions, and dust weather in China's Beijing-Tianjin Sand Source Region," Natural Hazards, vol. 62, no. 1, pp. 31-44, 2012.

[22] Z. T. Wu, J. J. Wu, J. H. Liu, B. He, T. Lei, and Q. F. Wang, "Increasing terrestrial vegetation activity of ecological restoration program in the Beijing-Tianjin Sand Source Region of China," Ecological Engineering, vol. 52, pp. 37-50, 2013.

[23] X. Li, H. Wang, S. Zhou, B. Sun, and Z. Gao, "Did ecological engineering projects have a significant effect on large-scale vegetation restoration in Beijing-Tianjin Sand Source Region, China? A remote sensing approach," Chinese Geographical Science, vol. 26, no. 2, pp. 216-228, 2016.

[24] B. Qu, W. Zhu, S. Jia, and A. Lv, "Spatio-temporal changes in vegetation activity and its driving factors during the growing season in China from 1982 to 2011," Remote Sensing, vol. 7, no. 10, pp. 13729-13752, 2015.

[25] J. Liu, J. Wu, Z. Wu, and M. Liu, "Response of NDVI dynamics to precipitation in the Beijing-Tianjin sandstorm source region," International Journal of Remote Sensing, vol. 34, no. 15, pp. 53315350, 2013.

[26] N. Shan, Z. Shi, X. Yang, J. Gao, and D. Cai, "Spatiotemporal trends of reference evapotranspiration and its driving factors in the Beijing-Tianjin Sand Source Control Project Region, China," Agricultural and Forest Meteorology, vol. 200, pp. 322333, 2015.

[27] Q. Lu and B. Wu, The Beijing-Tianjin Sand Source Region Phase II Project Team, 'Planning Research about The Beijing-Tianjin Sand Source Region Phase II Project', China Forestry press, Beijing, China, 2013.

[28] P. Frich, L. V. Alexander, P. Della-Marta et al., "Observed coherent changes in climatic extremes during the second half of the twentieth century," Climate Research, vol. 19, no. 3, pp. 193-212, 2002.

[29] E. L. J. Booth, J. M. Byrne, and D. L. Johnson, "Climatic changes in western North America, 1950-2005," International Journal of Climatology, vol. 32, no. 15, pp. 2283-2300, 2012.

[30] X. B. Zhang and F. Yang, RClimDex (1.0) User Manual, Climate Research Branch of Meteorological Service of Canada, 2004.
[31] S. Wang, M. Zhang, B. Wang, M. Sun, and X. Li, "Recent changes in daily extremes of temperature and precipitation over the western Tibetan Plateau, 1973-2011," Quaternary International, vol. 313-314, pp. 110-117, 2013.

[32] X. L. Wang and Y. Feng, RHtestsV4 User Manual, Climate Research Division, Atmospheric Science and Technology Directorate, Science and Technology Branch, Environment Canada, 2013.

[33] M. J. Manton, P. M. Della-Marta, M. R. Haylock et al., "Trends in extreme daily rainfall and temperature in southeast Asia and the south Pacific: 1961-1998," International Journal of Climatology, vol. 21, no. 3, pp. 269-284, 2001.

[34] T. C. Peterson, M. A. Taylor, R. Demeritte et al., "Recent changes in climate extremes in the caribbean region," Journal of Geophysical Research: Atmospheres, vol. 107, no. D21, pp. ACL 16-1-ACL 16-9, 1984.

[35] Z. Yan, P. D. Jones, T. D. Davies et al., "Trends of extreme temperatures in Europe and China based on daily observations," Climatic Change, vol. 53, no. 1, pp. 355-392, 2002.

[36] E. Aguilar, T. C. Peterson, P. R. Obando et al., "Changes in precipitation and temperature extremes in Central America and northern South America, 1961-2003," Journal of Geophysical Research: Atmospheres, vol. 110, no. 23, Article ID D23107, pp. $1-15,2005$.

[37] X. Zhang, E. Aguilar, S. Sensoy et al., "Trends in Middle East climate extreme indices from 1950 to 2003," Journal of Geophysical Research: Atmospheres, vol. 110, no. 22, Article ID D22104, 2005.

[38] A. M. G. Klein Tank, T. C. Peterson, D. A. Quadir et al., "Changes in daily temperature and precipitation extremes in central and south Asia," Journal of Geophysical Research: Atmospheres, vol. 111, no. 16, Article ID D16105, 2006.

[39] M. New, B. Hewitson, D. B. Stephenson et al., "Evidence of trends in daily climate extremes over southern and west Africa," Journal of Geophysical Research: Atmospheres, vol. 111, no. 14, 2006.

[40] L. A. Vincent, E. Aguilar, M. Saindou et al., "Observed trends in indices of daily and extreme temperature and precipitation for the countries of the western Indian Ocean, 1961-2008," Journal of Geophysical Research: Atmospheres, vol. 116, no. 10, Article ID D10108, 2011.

[41] H. B. Mann, "Nonparametric tests against trend," Econometrica, vol. 13, pp. 245-259, 1945.

[42] M. G. Kendall, Rank Correlation Methods, Charles Griffin, London, England, 4th edition, 1975.

[43] Z. Shi, N. Shan, L. Xu et al., "Spatiotemporal variation of temperature, precipitation and wind trends in a desertification prone region of China from 1960 to 2013," International Journal of Climatology, vol. 36, no. 13, pp. 4327-4337, 2016.

[44] Z. Shi, L. Xu, X. Yang et al., "Trends in reference evapotranspiration and its attribution over the past 50 years in the Loess Plateau, China: implications for ecological projects and agricultural production," Stochastic Environmental Research and Risk Assessment, vol. 31, no. 1, pp. 257-273, 2017.

[45] Z. X. Xu, K. Takeuchi, H. Ishidaira, and J. Y. Li, "Long-term trend analysis for precipitation in Asian Pacific FRIEND river basins," Hydrological Processes, vol. 19, no. 18, pp. 3517-3532, 2005.

[46] R. M. Hirsch, J. R. Slack, and R. A. Smith, "Techniques of trend analysis for monthly water quality data.," Water Resources Research, vol. 18, no. 1, pp. 107-121, 1982. 
[47] P. K. Sen, "Estimates of the regression coefficient based on Kendall's tau," Journal of the American Statistical Association, vol. 63, pp. 1379-1389, 1968.

[48] T. Salmi, A. Määttä, P. Anttila et al., "Detecting trends of annual values of atmospheric pollutants by the Mann-Kendal test and Sen's slope estimates the excel template application MAKESENS," Air Quality, no. 31, 2002.

[49] S. Yue, P. Pilon, B. Phinney, and G. Cavadias, "The influence of autocorrelation on the ability to detect trend in hydrological series," Hydrological Processes, vol. 16, no. 9, pp. 1807-1829, 2002.

[50] D. Jhajharia, Y. Dinpashoh, E. Kahya, R. R. Choudhary, and V. P. Singh, "Trends in temperature over Godavari River basin in Southern Peninsular India," International Journal of Climatology, vol. 34, no. 5, pp. 1369-1384, 2014.

[51] D. Jhajharia, Y. Dinpashoh, E. Kahya, V. P. Singh, and A. Fakheri-Fard, "Trends in reference evapotranspiration in the humid region of northeast India," Hydrological Processes, vol. 26, no. 3, pp. 421-435, 2012.

[52] G. Zhu, Y. He, T. Pu et al., "Spatial distribution and temporal trends in potential evapotranspiration over Hengduan Mountains region from 1960 to 2009," Journal of Geographical Sciences, vol. 22, no. 1, pp. 71-85, 2012.

[53] D. A. Jones, W. Wang, and R. Fawcett, "High-quality spatial climate data-sets for Australia," Australian Meteorological and Oceanographic Journal, vol. 58, no. 4, pp. 233-248, 2009.

[54] D. T. Price, D. W. McKenney, I. A. Nalder, M. F. Hutchinson, and J. L. Kesteven, "A comparison of two statistical methods for spatial interpolation of Canadian monthly mean climate data," Agricultural and Forest Meteorology, vol. 101, no. 2-3, pp. 81-94, 2000.

[55] P. A. Hancock and M. F. Hutchinson, "Spatial interpolation of large climate data sets using bivariate thin plate smoothing splines," Environmental Modelling \& Software, vol. 21, no. 12, pp. 1684-1694, 2006.

[56] D. Zuo, Z. Xu, H. Yang, and X. Liu, "Spatiotemporal variations and abrupt changes of potential evapotranspiration and its sensitivity to key meteorological variables in the Wei River basin, China," Hydrological Processes, vol. 26, no. 8, pp. 11491160, 2012.

[57] A. P. Cuervo-Robayo, O. Téllez-Valdés, M. A. Gómez-Albores, C. S. Venegas-Barrera, J. Manjarrez, and E. Martínez-Meyer, "An update of high-resolution monthly climate surfaces for Mexico," International Journal of Climatology, vol. 34, no. 7, pp. 2427-2437, 2014.

[58] Z. Ye and Z. Li, "Spatiotemporal Variability and Trends of Extreme Precipitation in the Huaihe River Basin, a Climatic Transitional Zone in East China," Advances in Meteorology, vol. 2017, Article ID 3197435, 15 pages, 2017.

[59] H. Yang, D. Yang, Q. Hu, and H. Lv, "Spatial variability of the trends in climatic variables across China during 1961-2010," Theoretical and Applied Climatology, vol. 120, no. 3-4, pp. 773783, 2015.

[60] Q.X. Li, W. J. Dong, W. Li et al., "Assessment of the uncertainties in temperature change in China during the last century," Chinese Science Bulletin, vol. 55, no. 19, pp. 1974-1982, 2010.

[61] Q. Tian, M. Prange, and U. Merkel, "Precipitation and temperature changes in the major Chinese river basins during 1957-2013 and links to sea surface temperature," Journal of Hydrology, vol. 536, pp. 208-221, 2016.

[62] S. Y. Chen, Y. Y. Shi, Y. Z. Guo, and Y. X. Zheng, "Temporal and spatial variation of annual mean air temperature in arid and semiarid region in northwest China over a recent 46 year period," Journal of Arid Land, vol. 2, no. 2, pp. 87-97, 2010.

[63] S. Chen, J. Wang, Y. Shi, and Z. Guo, "The change of annual mean temperature in Monsoon Area of East China," Resources Science, vol. 3, 2009.

[64] R. D. Jackson, S. B. Idso, and J. Otterman, "Surface albedo and desertification," Science, vol. 189, no. 4207, pp. 1012-1015, 1975.

[65] F. M. Vukovich, D. L. Toll, and R. E. Murphy, "Surface temperature and albedo relationships in Senegal derived from NOAA-7 satellite data," Remote Sensing of Environment, vol. 22, no. 3, pp. 413-421, 1987.

[66] R. Bintanja and J. Oerlemans, "The influence of the albedotemperature feed-back on climate sensitivity," Annals of Glaciology, vol. 21, pp. 353-360, 1995.

[67] T. Wang, W. Wu, X. Xue, Z. Han, W. Zhang, and Q. Sun, "Spatialtemporal changes of Sandy desertified land during last 5 decades in Northern China," Acta Geographica Sinica, vol. 59, no. 2, pp. 203-212, 2004.

[68] N. Zeng and J. Yoon, "Expansion of the world's deserts due to vegetation-albedo feedback under global warming," Geophysical Research Letters, vol. 36, no. 17, Article ID L17401, 2009.

[69] H. Pelgrum, T. Schmugge, A. Rango, J. Ritchie, and B. Kustas, "Length-scale analysis of surface albedo, temperature, and normalized difference vegetation index in desert grassland," Water Resources Research, vol. 36, no. 7, pp. 1757-1765, 2000.

[70] Z. Xuezhen, W. W. Chyung, F. Xiuqi, Y. Yu, and Z. Jingyun, "Agriculture development-induced surface albedo changes and climatic implications across northeastern china," Chinese Geographical Science, vol. 22, no. 3, pp. 264-277, 2012.

[71] C. Tong, J. Wu, S. Yong, J. Yang, and W. Yong, "A landscape-scale assessment of steppe degradation in the Xilin River Basin, Inner Mongolia, China," Journal of Arid Environments, vol. 59, no. 1, pp. 133-149, 2004.

[72] K. Kawada, W. W., and T. Nakamura, "Land degradation of abandoned croplands in the Xilingol steppe region, Inner Mongolia, China," Grassland Science, vol. 57, no. 1, pp. 58-64, 2011.

[73] J. Liang, J. Xia, L. Liu, and S. Wan, "Global patterns of the responses of leaf-level photosynthesis and respiration in terrestrial plants to experimental warming," Journal of Plant Ecology, vol. 6, no. 6, pp. 437-447, 2013.

[74] Z. Xu, H. Shimizu, S. Ito et al., "Effects of elevated CO2, warming and precipitation change on plant growth, photosynthesis and peroxidation in dominant species from North China grassland.", Planta, vol. 239, no. 2, pp. 421-435, 2014.

[75] M. Reyes-Fox, H. Steltzer, M. J. Trlica et al., "Elevated CO2 further lengthens growing season under warming conditions," Nature, vol. 510, no. 7504, pp. 259-262, 2014.

[76] J. S. Clark, J. Melillo, J. Mohan, and C. Salk, “The seasonal timing of warming that controls onset of the growing season," $G C B$ Bioenergy, vol. 20, no. 4, pp. 1136-1145, 2014.

[77] W. Wei, Z. Shi, X. Yang et al., "Recent trends of extreme precipitation and their teleconnection with atmospheric circulation in the Beijing-Tianjin Sand source region, China, 1960-2014," Atmosphere, vol. 8, no. 5, article no. 83, 2017.

[78] Z. Chen and G. Yang, "Analysis of drought hazards in North China: distribution and interpretation," Natural Hazards, vol. 65, no. 1, pp. 279-294, 2013.

[79] Y. Wang, B. Zhou, D. Qin, J. Wu, R. Gao, and L. Song, "Changes in mean and extreme temperature and precipitation over the arid region of northwestern China: Observation and 
projection," Advances in Atmospheric Sciences, vol. 34, no. 3, pp. 289-305, 2017.

[80] W. He, R. Bu, Y. Hu, Z. Xiong, and M. Liu, "Analysis of temporal and spatial characteristic of temperature change over the last 45 years in Northeastern China," Advanced Materials Research, vol. 518-523, pp. 1367-1370, 2012.

[81] J. Otterman, R. Atlas, S.-H. Chou et al., "Are stronger NorthAtlantic southwesterlies the forcing to the late-winter warming in Europe?" International Journal of Climatology, vol. 22, no. 6, pp. 743-750, 2002.

[82] G. J. Zhang, M. Cai, and A. Hu, "Energy consumption and the unexplained winter warming over northern Asia and North America," Nature Climate Change, vol. 3, no. 5, pp. 466-470, 2013.

[83] S. Bokhorst, J. W. Bjerke, F. W. Bowles, J. Melillo, T. V. Callaghan, and G. K. Phoenix, "Impacts of extreme winter warming in the sub-Arctic: Growing season responses of dwarf shrub heathland," GCB Bioenergy, vol. 14, no. 11, pp. 2603-2612, 2008.

[84] J. Liu, J. Xie, T. Gong, H. Wang, and Y. Xie, "Impacts of winter warming and permafrost degradation on water variability, upper Lhasa River, Tibet," Quaternary International, vol. 244, no. 2, pp. 178-184, 2011.

[85] Z. Jiang, T. Ma, and Z. Wu, "China coldwave duration in a warming winter: Change of the leading mode," Theoretical and Applied Climatology, vol. 110, no. 1-2, pp. 65-75, 2012.

[86] J. M. Wallace, I. M. Held, D. W. J. Thompson, K. E. Trenberth, and J. E. Walsh, "Global warming and winter weather," Science, vol. 343, no. 6172, pp. 729-730, 2014.

[87] B. Fan, L. Guo, N. Li et al., "Earlier vegetation green-up has reduced spring dust storms," Scientific Reports, vol. 4, article no. 6749, 2014.

[88] W. Xiong, I. P. Holman, L. You, J. Yang, and W. Wu, "Impacts of observed growing-season warming trends since 1980 on crop yields in China," Regional Environmental Change, vol. 14, no. 1, pp. 7-16, 2014.

[89] L. You, M. W. Rosegrant, S. Wood, and D. Sun, "Impact of growing season temperature on wheat productivity in China," Agricultural and Forest Meteorology, vol. 149, no. 6-7, pp. 10091014, 2009.

[90] K. Mix, V. L. Lopes, and W. Rast, "Growing season expansion and related changes in monthly temperature and growing degree days in the Inter-Montane Desert of the San Luis Valley, Colorado," Climatic Change, vol. 114, no. 3-4, pp. 723-744, 2012.

[91] J. Larkindale, M. Mishkind, and E. Vierling, "Plant responses to high temperature," in Plant Abiotic Stress, pp. 100-144, Blackwell Publishing, Hoboken, NJ, USA, 2005.

[92] G. Søgaard, A. Granhus, and Ø. Johnsen, "Effect of frost nights and day and night temperature during dormancy induction on frost hardiness, tolerance to cold storage and bud burst in seedlings of Norway spruce," Trees - Structure and Function, vol. 23, no. 6, pp. 1295-1307, 2009.

[93] D. B. Lobell, "Changes in diurnal temperature range and national cereal yields," Agricultural and Forest Meteorology, vol. 145, no. 3-4, pp. 229-238, 2007.

[94] M. Darand, A. Masoodian, H. Nazaripour, and M. R. Mansouri Daneshvar, "Spatial and temporal trend analysis of temperature extremes based on Iranian climatic database (1962-2004)," Arabian Journal of Geosciences, vol. 8, no. 10, pp. 8469-8480, 2015.

[95] P. Zhai and X. Pan, "Trends in temperature extremes during 1951-1999 in China," Geophysical Research Letters, vol. 30, no. 17, 2003.
[96] B. Nandintsetseg, J. S. Greene, and C. E. Goulden, "Trends in extreme daily precipitation and temperature near Lake Hövsgöl, Mongolia," International Journal of Climatology, vol. 27, no. 3, pp. 341-347, 2007.

[97] A. C. Kruger and S. S. Sekele, "Trends in extreme temperature indices in South Africa: 1962-2009," International Journal of Climatology, vol. 33, no. 3, pp. 661-676, 2013.

[98] L. Wang, Z. Wu, F. Wang, H. Du, and S. Zong, "Comparative analysis of the extreme temperature event change over Northeast China and Hokkaido, Japan from 1951 to 2011," Theoretical and Applied Climatology, vol. 124, no. 1-2, pp. 375-384, 2016.

[99] T. R. Karl, N. Nicholls, and A. Ghazi, "Clivar/GCOS/WMO workshop on indices and indicators for climate extremes workshop summary," Climatic Change, vol. 42, no. 1, pp. 3-7, 1999.

[100] D. Huang, Y. Qian, and J. Zhu, "Trends of temperature extremes in China and their relationship with global temperature anomalies," Advances in Atmospheric Sciences, vol. 27, no. 4, pp. 937946, 2010.

[101] X. Wu, Z. Wang, X. Zhou, C. Lai, and X. Chen, "Trends in temperature extremes over nine integrated agricultural regions in China, 1961-2011," Theoretical and Applied Climatology, vol. 129, no. 3-4, pp. 1279-1294, 2017.

[102] S. Solomon, D. Qin, M. Manning et al., Climate Change 2007: The Physical Science Basis. Contribution of Working Group I to The Fourth Assessment Report of The Intergovernmental Panel on Climate Change, Cambridge University Press, Cambridge, UK, 2007.

[103] O. K. Atkin, M. H. Turnbull, J. Zaragoza-Castells et al., "Light inhibition of leaf respiration as soil fertility declines along a post-glacial chronosequence in New Zealand: An analysis using the Kok method," Plant and Soil, vol. 367, no. 1-2, pp. 163-182, 2013.

[104] S. Peng, S. Piao, P. Ciais et al., "Asymmetric effects of daytime and night-time warming on Northern Hemisphere vegetation," Nature, vol. 501, no. 7465, pp. 88-92, 2013.

[105] S. Q. Wan, J. Y. Xia, W. X. Liu, and S. Niu, "Photosynthetic overcompensation under nocturnal warming enhances grassland carbon sequestration," Ecology, vol. 90, no. 10, pp. 27002710, 2009

[106] C. L. Liang, Q. Z. Yu, Y. J. Liu et al., "Effects of air temperature circadian on the NDVI of Nansi Lake Wetland Vegetation," Tropical Geography, vol. 35, no. 3, pp. 422-426, 2015 (Chinese).

[107] J. R. Welch, J. R. Vincent, M. Auffhammer, P. F. Moya, A. Dobermann, and D. Dawe, "Rice yields in tropical/subtropical Asia exhibit large but opposing sensitivities to minimum and maximum temperatures," Proceedings of the National Acadamy of Sciences of the United States of America, vol. 107, no. 33, pp. 14562-14567, 2010.

[108] J. Tan, S. Piao, A. Chen et al., "Seasonally different response of photosynthetic activity to daytime and night-time warming in the Northern Hemisphere," GCB Bioenergy, vol. 21, no. 1, pp. 377-387, 2015.

[109] H. Yu, J. Hammond, S. Ling, S. Zhou, P. E. Mortimer, and J. $\mathrm{Xu}$, "Greater diurnal temperature difference, an overlooked but important climatic driver of rubber yield," Industrial Crops and Products, vol. 62, pp. 14-21, 2014.

[110] J. Berner, T. V. Callaghan, H. Huntington et al., Impacts of a Warming Arctic: Arctic Climate Impact Assessment, Cambridge University Press, Cambridge, UK, 2004. 

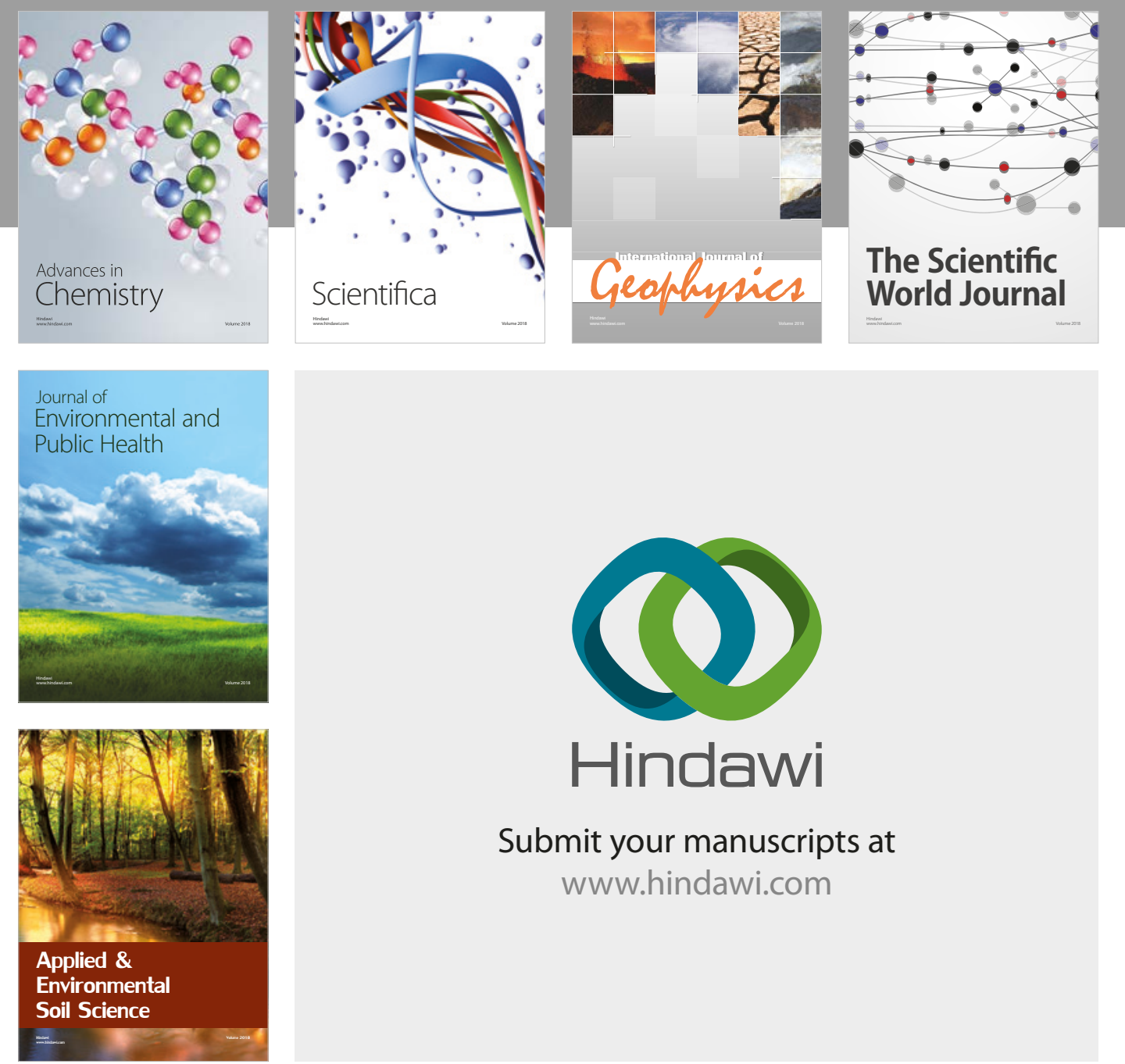

The Scientific

\section{World Journal}
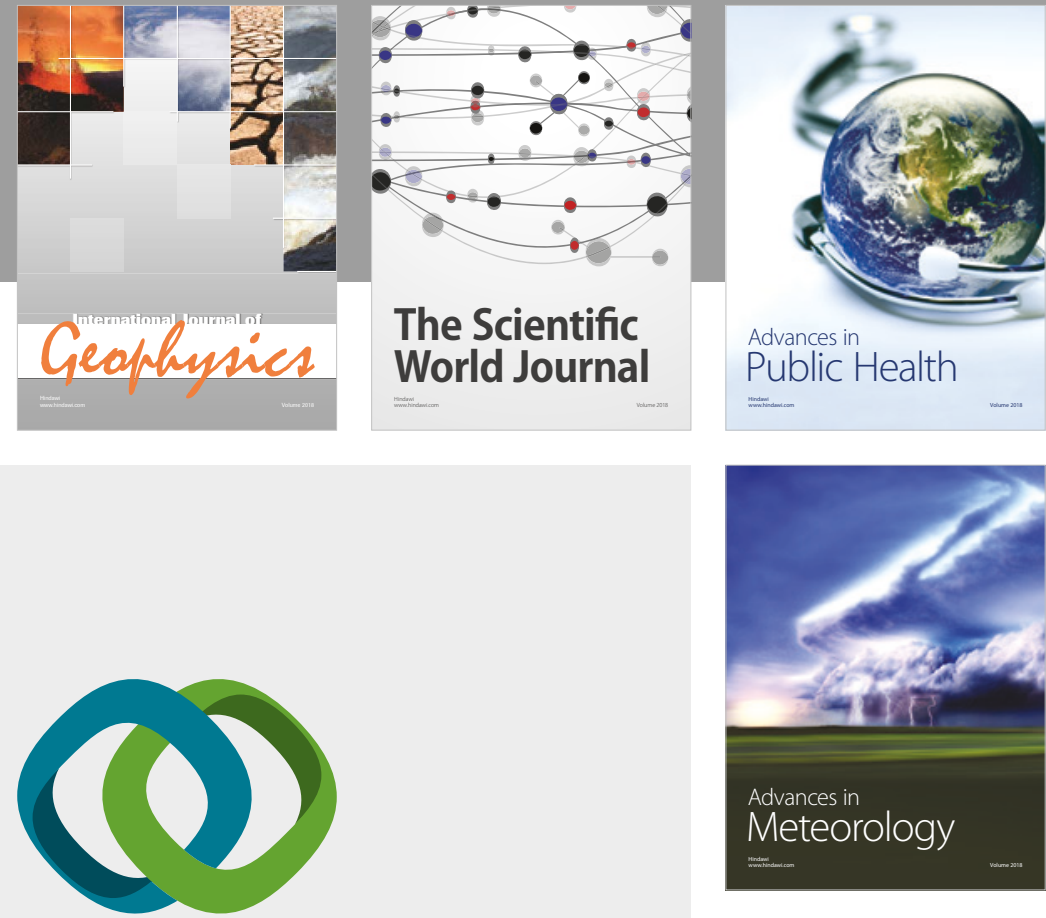

Advan

Public Health

\section{Hindawi}

Submit your manuscripts at

www.hindawi.com
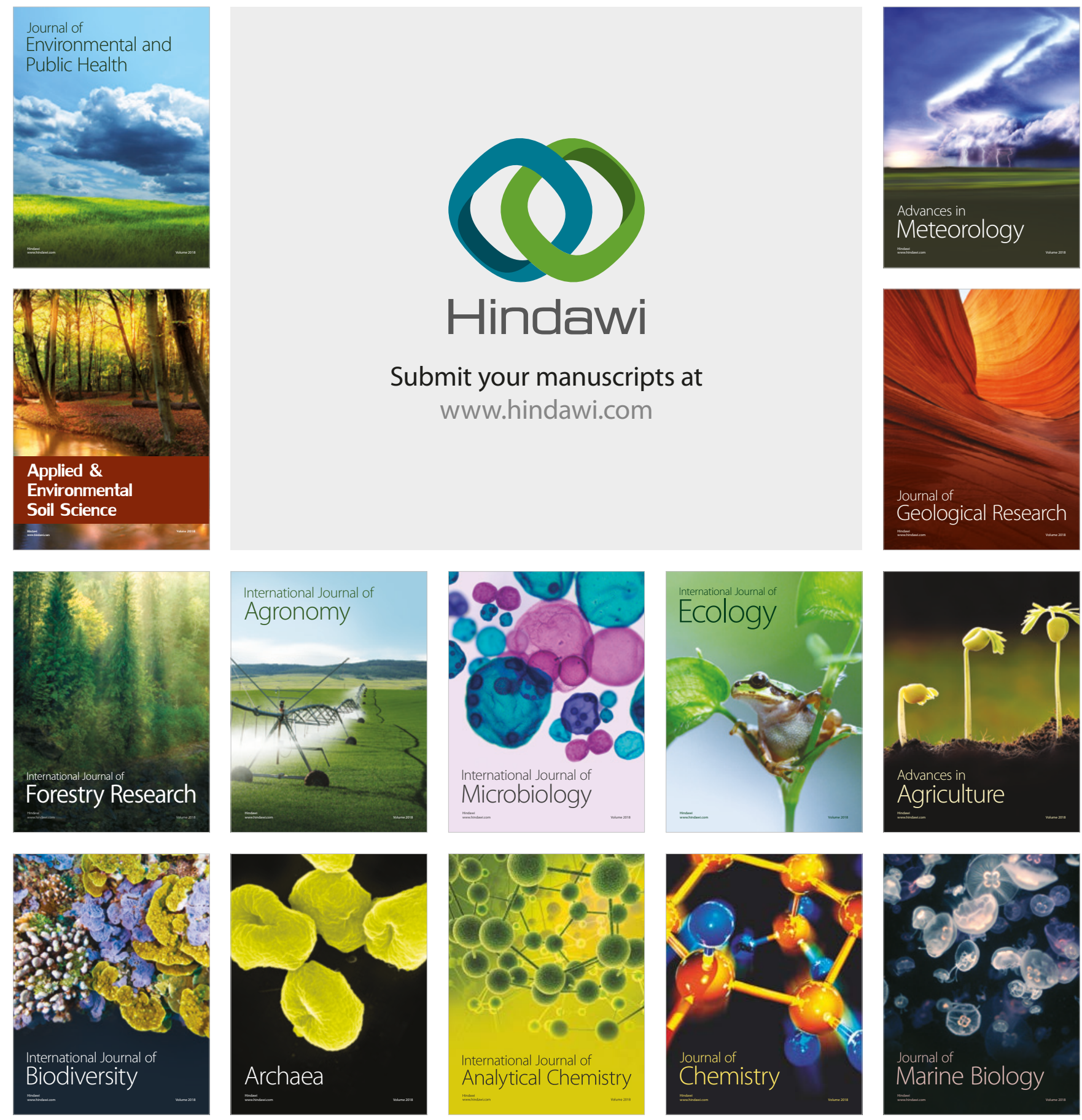